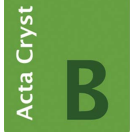

STRUCTURAL SCIENCE CRYSTAL ENGINEERING MATERIALS

ISSN 2052-5206

Received 26 July 2018

Accepted 26 September 2018

Edited by A. J. Blake, University of Nottingham, England

Keywords: isosaccharinate; gluconate; intermediate-level waste repositories; low-level waste repositories; crystal structure; synchrotron radiation.

CCDC references: $1846615 ; 1846616$

Supporting information: this article has supporting information at journals.iucr.org/b

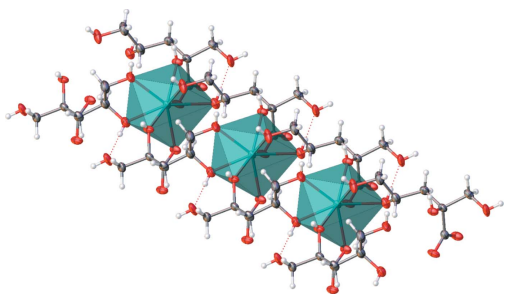

(C) 2018 International Union of Crystallography

\section{Crystal and solution structures of calcium complexes relevant to problematic waste disposal: calcium gluconate and calcium isosaccharinate}

\author{
V. Bugris, ${ }^{a}$ Cs. Dudás, ${ }^{b, c}$ B. Kutus, ${ }^{\text {b,g }}$ V. Harmat, ${ }^{\text {a,d }}$ K. Csankó, ${ }^{a}$ S. Brockhauser, ${ }^{\text {a,e }}$ \\ I. Pálinkó, ${ }^{\mathrm{c}, \mathrm{f}}$ Peter Turner ${ }^{\mathrm{a}, \mathrm{g} *}$ and P. Sipos ${ }^{\mathrm{b}, \mathrm{c} *}$
}

\begin{abstract}
${ }^{a}$ X-ray Crystallography Laboratory, Biological Research Center, HAC-BRC, Temesvári krt. 62, Szeged, H-6726, Hungary, ${ }^{\mathbf{b}}$ Department of Inorganic and Analytical Chemistry, University of Szeged, Szeged, H-6721, Dóm tér 7 Hungary, ${ }^{\mathbf{C}}$ Material and Solution Structure Research Group, Institute of Chemistry, University of Szeged, Szeged H-6721, Rerrich Béla tér 1 Hungary, ${ }^{\mathbf{d}}$ Laboratory of Structural Chemistry and Biology, Institute of Chemistry, Eötvös Loránd University, Budapest, Hungary, ${ }^{\mathbf{e}}$ European X-ray Free-Electron Laser Facility GmbH (EuXFEL), Holzkoppel 4, Schenefeld, 22869, Germany, 'Department of Organic Chemistry, University of Szeged, Dóm tér 8, Szeged, H-6721, Hungary, and ${ }^{\mathrm{g}}$ School of Chemistry, University of Sydney, Sydney, NSW 2006, Australia. *Correspondence e-mail: peter.turner@sydney.edu.au, sipos@chem.u-szeged.hu
\end{abstract}

The single-crystal structures of calcium D-gluconate and calcium $\alpha$-D-isosaccharinate have been determined using X-ray diffraction at $100 \mathrm{~K}$. Surprisingly, given its significance in industrial and medical applications, the structure of calcium D-gluconate has not previously been reported. Unexpectedly, the gluconate crystal structure comprises coordination polymers. Unusually, the calcium coordination number is nine. Adjacent metal centres are linked by three $\mu$-oxo bridges, with a metal-metal separation of 3.7312 (2) A. One of the gluconate ligands contradicts a suggestion from 1974 that a straight chain conformation is associated with an intramolecular hydrogen bond. This ligand binds to three adjacent metal centres. The use of synchrotron radiation provided an improved crystal structure with respect to that previously reported for the isosaccharinate complex, allowing the location of the hydroxy hydrogen sites to be elucidated. In contrast to the gluconate structure, there are no $\mu$-oxo bridges in the isosaccharinate coordination polymer and the isosaccharinate bridging coordination is such that the distance between adjacent metal centres, each of which is eight-coordinate, is 6.7573 (4) $\AA$. Complementing the crystal structure determinations, modelling studies of the geometries and coordination modes for the aqueous $[\mathrm{CaGluc}]^{+}$and $[\mathrm{CaIsa}]^{+}$complexes are presented and discussed.

\section{Introduction}

Small organic molecules that form during the decomposition of cellulose in alkaline environments have the potential to play a significant role in determining the environmental impact of two modern waste-streams: that of radioactive waste and that of landfill-containing cellulosic waste together with the ash of municipal solid waste incineration. The main product of this decomposition is $(2 S, 4 R)-5$ trihydroxy-(2S)-(hydroxymethyl)pentanoic acid ( $\alpha$-D-isosaccharinic acid, $\alpha$-HIsa, Scheme 1). The other important compound is $(2 R, 3 S, 4 R, 5 R)-2,3,4,5,6$-pentahydroxyhexanoic acid (D-gluconic acid, HGluc, Scheme 1) which is used as an additive for the formulation of cementitious materials. Elucidating the interactions between these polyhydroxy carboxylic acids and waste stream metals will inform the assessment of the risk and management options for these wastes. 


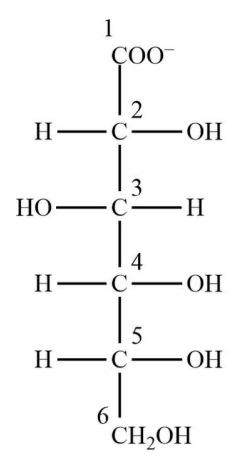

D-gluconate

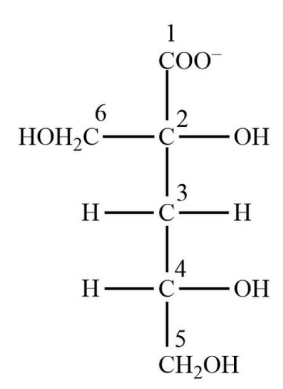

$\alpha$-D-isosaccharinate Scheme 1

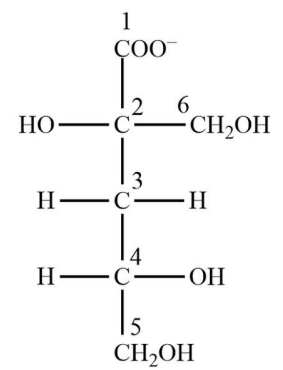

$\beta$-D-isosaccharinate
The safe storage of radioactive waste arising from nuclear power generation and nuclear weapon manufacturing is a long-standing and as yet unresolved problem. Cement is the leading candidate for the storage of intermediate and lowlevel waste material because it is considerably cheaper than glass or ceramic alternatives. Questions remain, however, about the long-term containment of radioactive waste within cement containers and repositories.

Cement pore water remains above $\mathrm{pH} 12.5$ for periods in the order of $10^{5}$ years (Berner, 1990) and the near-field $\mathrm{pH}$ of a cementitious geological repository may remain above $\mathrm{pH} 12.0$ for hundreds to thousands of years (Nuclear Decommissioning Agency, 2010). In principle, this hyperalkaline environment should suppress radionuclide mobility by causing (i) precipitation of the radioactive metal hydroxides and (ii) their sorption on the cement matrix. However, the presence of organic ligands, notably cellulose decomposition products, is known to reduce the sorption and immobilization of actinides (Berry et al., 1991; Baston et al., 1992, 1994; Van Loon et al., 1999) and may lead to environmental contamination. Intermediate and low-level nuclear wastes may contain substantial amounts of cellulose-containing materials. In Switzerland for example, some $50 \%$ of the radioactive organic waste (cotton, paper products, wood) may be cellulosic (NAGRA, 1990; Van Loon et al., 1997).

Under the highly alkaline conditions present in concretebased containers, cellulose breaks down into relatively lowmolecular-weight carboxylates and polyhydroxy carboxylates (Van Loon \& Glaus, 1998). In the presence of calcium, the principal breakdown products, up to $80 \%$, are approximately equal amounts of $\alpha$-D-isosaccharinate $\left(\alpha\right.$-Isa $\left.{ }^{-}\right)$and its epimer $\beta$-D-isosaccharinate $\left(\beta\right.$-Isa $\left.{ }^{-}\right)$(Van Loon \& Glaus, 1998; Glaus et al., 1999; Knill \& Kennedy, 2003; Almond et al., 2016). Research attention to date has focused almost entirely on $\alpha$-Isa ${ }^{-}$as the key ligand, in part because until recently $\beta$-Isa ${ }^{-}$ has been notably difficult to obtain (Van Loon \& Glaus, 1998; Glaus et al., 1999; Knill \& Kennedy, 2003; Almond et al., 2016; Shaw et al., 2012). Additionally, $\alpha$-Isa ${ }^{-}$has been found to be the more effective ligand (Shaw et al., 2012; Glaus \& Van Loon, 2008), though recent work suggests this may depend on the metal in question (Almond et al., 2016).
D-Gluconate $\left(\mathrm{Gluc}^{-}\right)$is another important cellulosic degradation product in alkaline environments and it may also be present as a plasticizer added in the preparation of concrete (Van Loon \& Glaus, 1998; Glaus et al., 2006). Gluconate-based concrete admixtures are used for the cement-based conditioning of waste matrices (Wieland \& Van Loon, 2003). The concentration of $\mathrm{Gluc}^{-}$in cement pore waters may range from $10^{-5}$ to $10^{-2} M$ (Gaona et al., 2008), which is several orders of magnitude lower than that of $\mathrm{Isa}^{-}$, which could reach $0.1 \mathrm{M}$ (Van Loon \& Glaus, 1997). Gluconate is notable in having the largest effect on the uptake of tri- and tetravalent radioelements by hardened cement paste (Wieland \& Van Loon, 2003).

Also environmentally problematic is the co-disposal of cellulosic waste and municipal solid waste incineration dry scrubber residue in landfill, where the alkaline degradation of cellulose may mobilize metals from the dry scrubber residue (Svensson et al., 2007). It has been estimated that as a consequence, an additional 29 tons of $\mathrm{Pb}, 39$ tons of $\mathrm{Zn}$ and 17 tons of $\mathrm{Cu}$ is leached annually in Sweden. The same study found the presence of $\mathrm{CaIsa}_{2}$ influenced the leaching process. The presence of calcium is an important consideration, as the limited solubility of its complexes with $\mathrm{Gluc}^{-}$and $\alpha$-Isa ${ }^{-}$(Rai et al., 1998) can limit the concentration of these complexants and accordingly moderate their waste stream influence. It has been estimated that the concentration of calcium in cement pore water is between $2 \times 10^{-3}$ and $3 \times 10^{-2} M$ (Berner, 1992).

In being structurally similar, Gluc ${ }^{-}$has been widely used as a readily available analogue for $\alpha$-Isa ${ }^{-}$, for which extraction and purification has been challenging and time consuming (Glaus et al., 2006; Giroux et al., 2002; Tits et al., 2005; Zhang et al., 2007; Zhang et al., 2009; Colàs et al., 2013a,b; Rojo et al., 2013; Dudás et al., 2017). It has been recently shown though, that there are some fundamental differences between the complexing properties of the two ligands in alkaline medium in the presence of calcium (Dudás et al., 2017). While highly alkaline Gluc $^{-}$-containing solutions are predominated by multinuclear calcium complexes, Isa $^{-}$was shown to be unable to form such multinuclear species. This suggests that caution should be exercised when using Gluc ${ }^{-}$as an analogue for Isa ${ }^{-}$ (Dudás et al., 2017; Birjkumar et al., 2012).

Solution and computational studies (Tajmir-Riahi, 1990; Pallagi et al., 2010) suggest that in neutral or weakly alkaline environments a mononuclear $[\mathrm{CaGluc}]^{+}$species predominates. Under these conditions the multidentate ligand forms a fiveor six-membered chelate involving $\mathrm{O} 1$ (oxygen attached to $\mathrm{C} 1$; see Fig. 1) and $\mathrm{O} 2$ or $\mathrm{O} 3$ coordination with the further possibility of a head-to-tail complex involving O6 coordination (Dudás et al., 2017; Pallagi et al., 2010). There is also evidence (Pallagi et al., 2010; Masone \& Vicedomini, 1981) suggesting the formation of a neutral $\left[\mathrm{CaGluc}_{2}\right]^{0}$ complex in the presence of high ligand concentrations.

Solution and computational studies (Dudás et al., 2017) for neutral solutions suggest a $[\mathrm{CaIsa}]^{+}$species with tridentate coordination involving a carboxylate oxygen and the $\mathrm{O} 4$ and O6 hydroxy groups. Lack of participation of the $\mathrm{O} 2$ hydroxy 
Table 1

Experimental details.

(I)

Crystal data

Chemical formula

$M_{\mathrm{r}}$

Crystal system, space group

Temperature (K)

$a, b, c(\AA)$

$V\left(\AA^{3}\right)$

$D_{c}\left(\mathrm{~g} \mathrm{~cm}^{-3}\right)$

$Z$

Radiation type

$\mu\left(\mathrm{mm}^{-1}\right)$

Crystal size (mm)

Data collection

Diffractometer

Absorption correction

$T_{\min }, T_{\max }$

No. of measured, independent and observed

$[I>2 \sigma(I)]$ reflections

$R_{\text {int }}$

$(\sin \theta / \lambda)_{\max }\left(\AA^{-1}\right)$

Refinement

$R\left[F^{2}>2 \sigma\left(F^{2}\right)\right], w R\left(F^{2}\right), S$

No. of reflections

No. of parameters

No. of restraints

$\mathrm{H}$-atom treatment

$\Delta \rho_{\max }, \Delta \rho_{\min }\left(\mathrm{e} \AA^{-3}\right)$

Absolute structure

Absolute structure parameter

\author{
$\mathrm{Ca}^{2+} \cdot\left(\mathrm{C}_{6} \mathrm{H}_{11} \mathrm{O}_{7}^{-}\right)_{2} \cdot \mathrm{H}_{2} \mathrm{O}$ \\ 448.39 \\ Orthorhombic, $P 2_{1} 2_{1} 2_{1}$ \\ 100 \\ 6.71198 (9), 13.36410 (17), 19.5439 (3) \\ 1753.08 (4) \\ 1.699 \\ 4 \\ Mo $K \alpha$ \\ 0.44 \\ $0.11 \times 0.03 \times 0.02$
}

AFC12 kappa

Multi-scan CrysAlis PRO 1.171.39.28e

(Rigaku Oxford Diffraction, 2015)

$0.898,1.00$

$77828,9212,8854$

0.034

0.870

$0.023,0.057,1.19$

9212

301

0

$\mathrm{H}$ atoms treated by a mixture of indepen-

dent and constrained refinement

$0.42,-0.22$

Flack $x$ determined using 3689 quotients

$[(I+)-(I-)] /[(I+)+(I-)]$ (Parsons et al., 2013)

$0.009(5)$
(II)

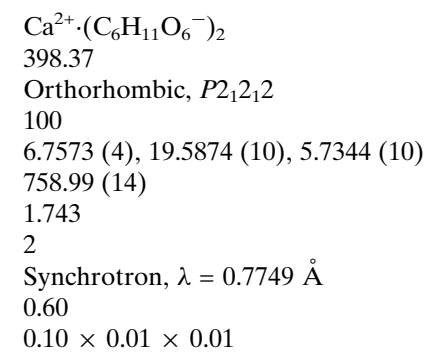

Pilatus 6M-F $(25 \mathrm{~Hz})$ and MD2 mini-kappa $-$

$4539,1394,1393$

0.069

0.616

$0.033,0.082,1.07$

1394

131

2

$\mathrm{H}$ atoms treated by a mixture of independent and constrained refinement $0.29,-0.60$

Flack $x$ determined using 541 quotients $[(I+)-(\mathrm{I}-)] /[(I+)+(I-)]($ Parsons et al., 2013).

$0.050(19)$

Computer programs: CrysAlis PRO (v1.171.39.28e; Rigaku Oxford Diffraction, 2015), mxCuBE (v2; Gabadinho et al., 2010), XDS (Kabsch, 2010), SHELXT (Sheldrick, 2015a), SHELXL2017/1 (Sheldrick, 2015b), OLEX2 (Dolomanov et al., 2009), SHELXLE (Hübschle et al., 2011), WinGX (Farrugia, 1999, 2012), ORTEP for Windows (Farrugia, 2012), PLATON (Spek, 2003), XNPP (Parsons et al., 2013; available on request from Prof. Simon Parsons, University of Edinburgh).

group in the metal binding, distinguishing isosaccharinate and gluconate complexation with calcium, might rationalize the apparent absence of a $\left[\mathrm{CaIsa}_{2}\right]^{0}$ complex in solution.

Herein we describe the crystal structures of the calcium complexes of $\mathrm{Gluc}^{-}$and $\alpha$-Isa ${ }^{-}$, augmenting the work we (Dudás et al., 2017; Pallagi et al., 2010, 2013, 2014) and others have undertaken to discern the solution interactions between the metal and the two multidentate carboxylates. A crystal structure was determined for CaIsa $\mathrm{C}_{2}$ in 1968 by Norrestam et al. (1968); however, the small sample size and the available equipment limited the detail obtained for the structure. The use of synchrotron data has provided an improved structure.

Given its industrial and medical significance, it is perhaps surprising that a crystal structure has not previously been reported for the calcium gluconate complex. This may be because the traditional method of slowly cooling an aqueous solution produces very fine needles with correspondingly weak X-ray diffraction. We obtained thicker crystals providing good quality data on a laboratory diffractometer by utilizing the hanging drop method and systematically optimizing crystal growth conditions. The data obtained for both the gluconate and isosaccharinate complexes provided the location of electron density associated with the hydrogen sites.
Complementing the crystal structure determinations, modelling studies of the geometries and coordination modes for the aqueous $[\mathrm{CaGluc}]^{+}$and $[\mathrm{CaIsa}]^{+}$complexes are presented and discussed.

\section{Experimental}

\subsection{Sample preparation and crystal growth}

Calcium D-gluconate (Sigma-Aldrich, $\geq 99 \%$ ) was used without further purification. Calcium $\alpha$-D-isosaccharinate was prepared according to the method of Whistler and BeMiller (1963). Successful synthesis was established using powder $\mathrm{X}$-ray diffractometry and as ${ }^{1} \mathrm{H}$ and ${ }^{13} \mathrm{C}$ NMR spectroscopies.

Attempts to grow single crystals using the conventional method of slowly cooling saturated aqueous solutions $(\mathrm{pH} \simeq$ 7-8) of calcium gluconate produced thin needles ill-suited to $\mathrm{X}$-ray diffraction analysis. Accordingly, a systematic crystallization screening process was undertaken using the hanging drop vapour diffusion method in plates containing 24 wells, with varying sample concentration, precipitant type and precipitant concentration. The sample concentration was varied between 10 and $100 \%$ by diluting a saturated solution 
of $\mathrm{CaIsa}_{2}$ with either water or the precipitant. The drop size varied between $4 \mu \mathrm{L}$ and $12 \mu \mathrm{L}$. Several aliphatic alcohols (methanol, ethanol, propanol, 2-propanol), ethylene glycol and $\mathrm{PEG}_{200}$ were tried as precipitants, either in pure form or diluted to $20-80 \%$ with water. The reservoir volume was $500 \mu \mathrm{L}$ or $1 \mathrm{ml}$. Suitable crystals were grown from $4 \mu \mathrm{L}$ saturated aqueous solutions of $\mathrm{CaGluc}_{2}$ diluted with $4 \mu \mathrm{l}$ of $80 \%$ ethylene glycol as the precipitant over a $1 \mathrm{ml}$ precipitant reservoir. Crystals were visible after several days and grew to approximately $0.05 \mathrm{~mm} \times 0.02 \mathrm{~mm} \times 0.01 \mathrm{~mm}$.

Crystals of calcium isosaccharinate were obtained over several days by methanol diffusion into a saturated aqueous solution $(\mathrm{pH} \simeq 7-8)$ of the compound. One millilitre of this saturated solution was pour into a glass tube of approximately $15 \mathrm{~mm}$ diameter, which was then placed inside a container containing $5 \mathrm{ml}$ of methanol. The container lid was then closed. This produced crystals of approximately $0.4 \mathrm{~mm} \times$ $0.1 \mathrm{~mm} \times 0.1 \mathrm{~mm}$.

\subsection{X-ray diffraction analysis}

2.2.1. General. Computations and visualization were carried out with WinGX (Farrugia, 1999; 2012), ShelXle (Hübschle et al., 2011), OLEX2 (Dolomanov et al., 2009), Vesta (Momma \& Izumi, 2011) and Xtal (Hall et al., 2000). The structures were obtained by direct methods using SHELXT (Sheldrick, 2015a) and extended and refined with SHELXL2017/1 (Sheldrick, 2008; Sheldrick, 2015b). The nonhydrogen atoms were modelled with anisotropic displacement and, in general, a riding atom model was used for the hydrogen atoms. The hydroxy hydrogen sites were located in final difference maps and modelled with isotropic displacement parameters. Crystallographic details for both $\mathrm{CaGluc}_{2} \cdot \mathrm{H}_{2} \mathrm{O}$ and $\mathrm{CaIsa}_{2}$ are provided in Table 1 .

2.2.2. Calcium gluconate. Data were collected at the UK National Crystallography Facility at the University of Southampton (Coles \& Gale, 2012). A colourless block-like crystal was attached with Exxon Paratone $\mathrm{N}$ to a short length of fibre supported on a thin piece of copper wire inserted into a copper mounting pin on a magnetic base. The crystal was quenched at 100 (1) $\mathrm{K}$ in a cold nitrogen gas stream from an Oxford Cryosystems Cryostream. Data were collected with $\omega$ scans to $76^{\circ} 2 \theta$ using a Rigaku FRE instrument generating $\mathrm{Mo} K \alpha$ radiation from a rotating anode and equipped with an AFC12 kappa goniometer and a HyPix 6000 detector. Data processing was undertaken with CrysAlisPro (Rigaku Oxford Diffraction, 2015) and included a multi-scan absorption correction. Empirical absorption correction used spherical harmonics, implemented in SCALE3 ABSPACK scaling algorithm. The structure was solved in the Sohncke space group $P 22_{1} 2_{1} 2_{1}$ (No. 19). The asymmetric unit contains a $\mathrm{Ca}\left(\mathrm{C}_{6} \mathrm{H}_{11} \mathrm{O}_{7}\right)_{2}$ calcium gluconate complex together with a water molecule. The absolute structure was reliably established with the Flack parameter (Parsons et al., 2013; Flack, 2014) refining to 0.009 (5).

2.2.3. Calcium isosaccharinate. A colourless needle-like crystal was attached with Exxon Paratone $\mathrm{N}$ to a nylon loop and quenched at 100 (1) $\mathrm{K}$ in a cold nitrogen gas stream from an Oxford Cryojet. A Pilatus 6M-F $(25 \mathrm{~Hz})$ and MD2 minikappa diffractometer (Brockhauser et al., 2013) were used for the data collection, employing $0.7749 \AA$ A silicon double-crystal monochromated synchrotron radiation at the EMBL PETRA III P13-MX1 beamline (Burkhardt et al., 2016). Data were collected with $\omega$ scans to $57^{\circ} 2 \theta$ using $m x C u B E 2$ (Gabadinho et al., 2010). Data processing was undertaken with $X D S$ (Kabsch, 2010). The structure was solved in the Sohncke space group $P 2_{1} 22$ (No. 18). The orthorhombic cell setting differs from that used for the 1968 structure, with the setting for the latter having the longest axis assigned as the $a$ axis. The asymmetric unit contains half a $\mathrm{Ca}\left(\mathrm{C}_{6} \mathrm{H}_{11} \mathrm{O}_{6}\right)_{2}$ calcium isosaccharinate complex, with the metal residing on a twofold axis. Distance restraints were used for the $\mathrm{H} 5 \mathrm{O}$ and $\mathrm{H} 6 \mathrm{O}$ model atoms. The absolute structure was established with the Flack parameter (Parsons et al., 2013; Flack, 2014) refining to $0.06(2)$.

\subsection{Molecular modelling}

In order to find the lowest-energy structures for the [CaGluc $^{+}$and $[\mathrm{CaIsa}]^{+}$complexes, quantum chemical calculations were made using the Gaussian09 (Frisch et al., 2009) software package. The structure optimizations were performed at the B3LYP level (Becke, 1988; Lee et al., 1988) using the $6-311++\mathrm{g}(\mathrm{d}, \mathrm{p})$ basis set, which was found to be appropriate in characterizing the hydration of $\alpha$ - and $\beta$-Dglucopyranoses (Momany et al., 2004). Furthermore, the B3LYP method was utilized to characterize the hydration shell of $\mathrm{Ca}^{2+}$ (Carl \& Armentrout, 2012).

As a first step, initial geometries differing in the coordination mode were optimized in vacuum. Then the Conductorlike Polarizable Continuum Model was utilized (Tomasi et al., 2005), with a framework of implicit water molecules. Finally, four explicit water molecules were introduced to the optimized structures to provide a more realistic representation of the environment of the first coordination shell of $\mathrm{Ca}^{2+}$. Of note, this approach has not been applied previously (Pallagi et al., 2010). The coordination number $(\mathrm{CN})$ of $\mathrm{Ca}^{2+}$ in $\mathrm{CaCl}_{2}$ solutions usually varies between 6 and 8 as was deduced from X-ray diffraction (XRD) (Bol et al., 1970; Albright, 1972; Probst et al., 1985; Megyes et al., 2004) and neutron diffraction (ND) (Cummings et al., 1980; Hewish et al., 1982; Badyal et al., 2004; Megyes et al., 2006) (XRD and ND), EXAFS studies (Spångberg et al., 2000; Tongraar et al., 2010) and molecular dynamics (MD) simulations (Di Tommaso et al., 2014). These $\mathrm{CNs}$ have been reported to be the most frequent found for calcium in the crystal structures in the Cambridge Structural Database (CSD) (Groom et al., 2016); see also Fig. 4 herein. Hence, in our initial structures the $\mathrm{CN}$ of the metal ion was set at 6 or 7 depending on the denticity of the ligand. The stability of each structure was checked with frequency calculations. 


\section{Results and discussion}

\subsection{Structural characterization of calcium(II) gluconate}

As Fig. 1 illustrates, the asymmetric unit of the calcium gluconate structure contains a neutral $\left[\mathrm{CaGluc}_{2}\right]^{0}$ complex of the type thought to be present in aqueous solutions having high ligand concentrations, together with a water solvate molecule. The structure is orthorhombic with non-centrosymmetric $P 2_{1} 2_{1} 2_{1}$ symmetry and comprises one-dimensional coordination polymers (see Fig. 2) parallel to the $a$ axis (see Figs. S1 and S2 in the supporting information). Both carboxylate oxygen O1 (O1_1; numbering scheme in Fig. 1) of one of the two crystallographically unique gluconate ligands (referred to herein as Gluc1) and hydroxy O2 (O2_2) of the second crystallographically unique ligand (Gluc2) bridge the calcium ion of the asymmetric unit and an adjacent symmetry-

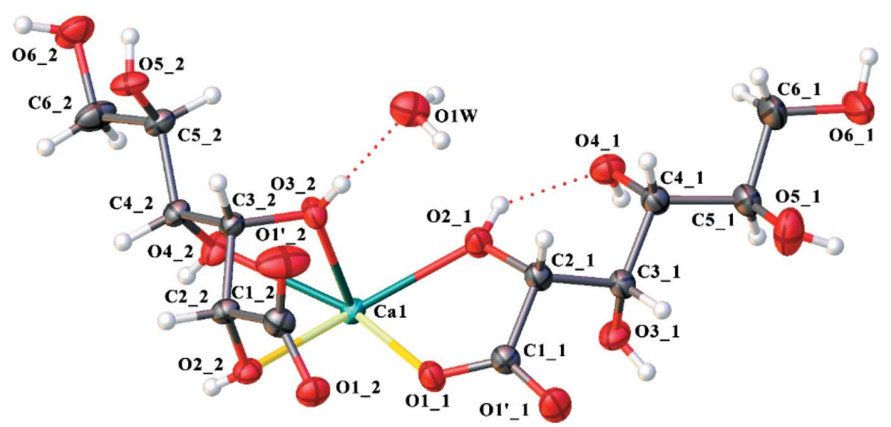

Figure 1

The asymmetric unit of the single-crystal structure of $\mathrm{CaGluc}_{2} \cdot \mathrm{H}_{2} \mathrm{O}$ (at $100 \mathrm{~K}$ ) with displacement ellipsoids shown at the $95 \%$ level and bridging bonds highlighted.

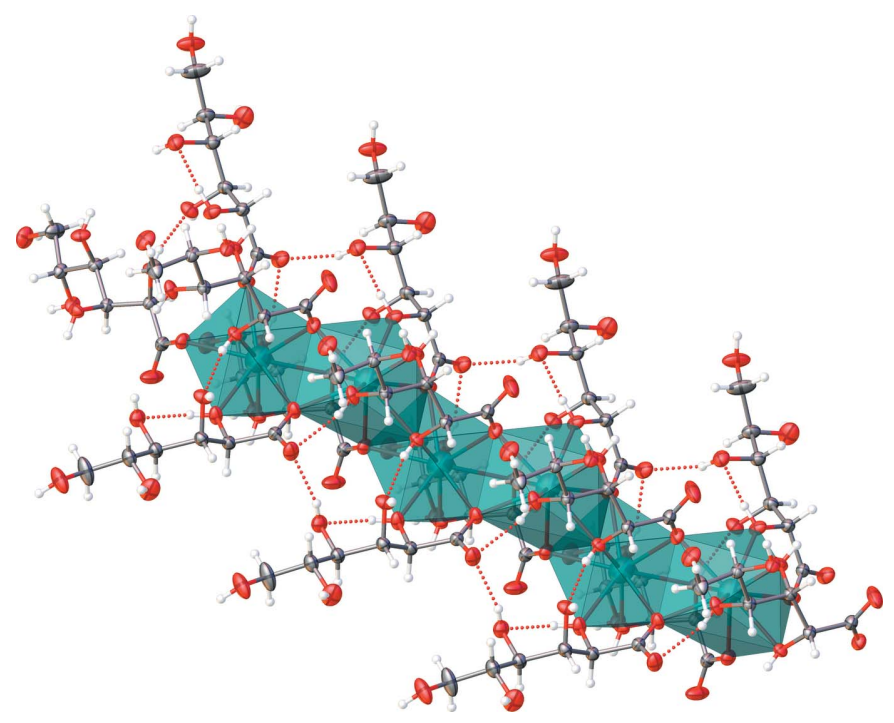

Figure 2

A hexanuclear segment of a coordination polymer in the $100 \mathrm{~K}$ singlecrystal structure of $\mathrm{CaGluc}_{2} \cdot \mathrm{H}_{2} \mathrm{O}$ showing the face-sharing distorted triaugmented triangular prism-shaped coordination polyhedra (see also Figs. S1 and S2 in the supporting information). The distance between adjacent metal centres within a polymer is 3.7312 (2) $\AA$. The displacement ellipsoids are shown at the $95 \%$ probability level, with those of the calcium ion enlarged by a factor of two for emphasis (see also Fig. 3). related calcium ion (Fig. 3). There is an additional $\mu$-oxo bridge, with the third being provided by the carboxylate oxygen $\mathrm{O} 1$ of a gluconate related by symmetry to the second of the asymmetric unit (O1_2 of Gluc2) by a screw axis in the $a$ direction. The metal-to-metal distance in the calcium gluconate structure is 3.7312 (2) $\AA$; selected bond lengths are provided in Table 2 .

The calcium ion coordination polyhedron is that of a distorted triaugmented triangular prism and, as Fig. 2 suggests, adjoining polyhedral of a given polynuclear chain share a triangular face. The calcium ion is coordinated to nine oxygen atoms (see Fig. S3 in the supporting information), five of which are from the two gluconate ligands of the asymmetric unit (Tables 2 and 3 for a summary of the coordination geometry). Three of the asymmetric unit donors are hydroxy $\mathrm{O}$ atoms of gluconate Gluc2 (O2_2, O3_2, O4_2), whereas the other two are a carboxylate oxygen (O1_1) (numberings scheme shown in Fig. 1; also see Fig. S4 in the supporting information) and a hydroxy oxygen (O2_1) of gluconate Gluc1. Although neither of the carboxylate oxygen atoms of the Gluc2 ligand coordinate with the calcium ion of the asymmetric unit, the $\mathrm{O} 1$ of this ligand coordinates with the adjacent calcium that is bridged by the $\mathrm{O} 1$ oxygen of the Gluc1 ligand. The O1 oxygen of Glu2 additionally bridges to the next calcium in the chain and, remarkably, this ligand then binds to three adjacent metal centres (see Fig. S5).

The CSD (Groom et al., 2016) currently has 31 entries for structures with calcium ions bridged by three oxygen atoms. The average calcium-calcium distance in these structures is 3.4 (2) $\AA$, with the maximum being $3.8 \AA$ and the minimum being $2.9 \AA$. One of the CSD held structures is a coordination polymer and in this structure, that of $\left[\mathrm{Ca}_{9}\left(\mu-\mathrm{H}_{2} \mathrm{O}\right)_{9^{-}}\right.$ (picolinate) $\left.)_{18}\right] \cdot 4 \mathrm{H}_{2} \mathrm{O}$ (CSD reference CABBUF; Nair et al.,

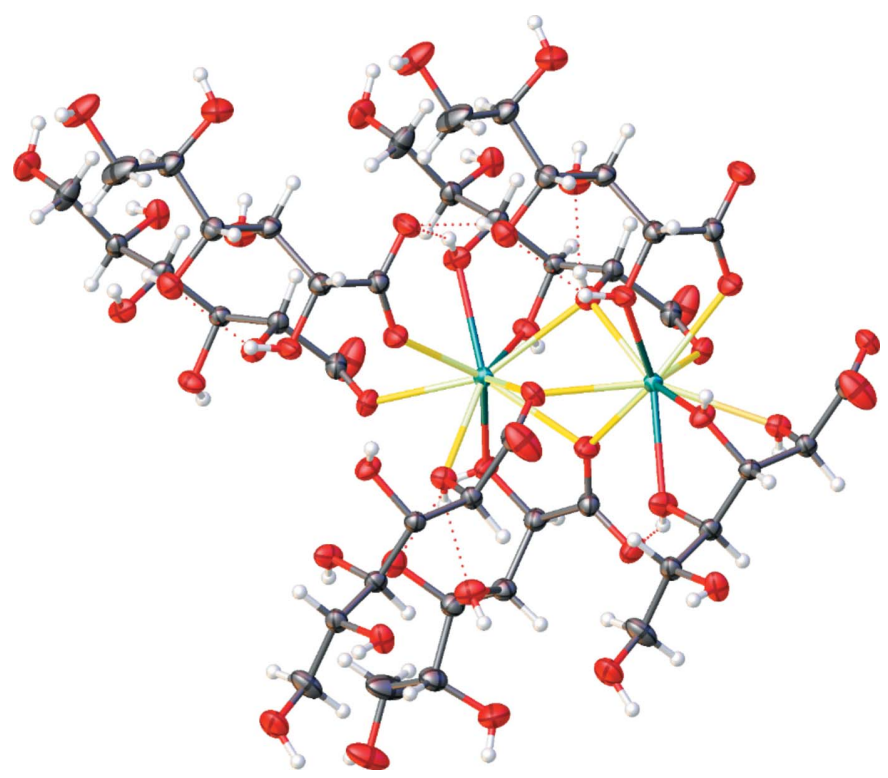

Figure 3

A dinuclear segment of a polynuclear chain in the $100 \mathrm{~K}$ single-crystal structure of $\mathrm{CaGluc}_{2} \cdot \mathrm{H}_{2} \mathrm{O}$, with the bridging bonds highlighted. The displacement ellipsoids are shown at the $95 \%$ level. 
Table 2

Selected distances $(\AA)$ for $\mathrm{CaGluc}_{2} \cdot \mathrm{H}_{2} \mathrm{O}(\mathrm{I})$.

\begin{tabular}{llllll}
\hline Atoms & & Distance & Atoms & Distance \\
\hline $\mathrm{Ca} 1$ & O3_2 & $2.4123(7)$ & $\mathrm{Ca} 1$ & $\mathrm{O} 2 \_1$ & $2.4370(8)$ \\
$\mathrm{Ca} 1$ & O4_2 & $2.4467(7)$ & $\mathrm{Ca} 1$ & $\mathrm{O} 22^{\mathrm{i}}$ & $2.4476(7)$ \\
$\mathrm{Ca} 1$ & O1_2 & $2.4661(8)$ & $\mathrm{Ca} 1$ & $\mathrm{O} 1 \_22^{\mathrm{ii}}$ & $2.4739(7)$ \\
$\mathrm{Ca} 1$ & O1_1 & $2.4837(7)$ & $\mathrm{Ca} 1$ & $\mathrm{O} 11^{\mathrm{i}}$ & $2.5023(7)$ \\
$\mathrm{Ca} 1$ & O2_2 & $2.6291(7)$ & $\mathrm{Ca} 1$ & $\mathrm{Ca} 1$ 1ii & $3.7312(2)$ \\
\hline
\end{tabular}

Symmetry codes: (i) $x+\frac{1}{2}, \frac{1}{2}-y, 1-z$; (ii) $1+x, y, z$; (iii) $x-\frac{1}{2}, \frac{1}{2}-y, 1-z$.

Table 3

Selected bond angles $\left({ }^{\circ}\right)$ for $\mathrm{CaGluc}_{2} \cdot \mathrm{H}_{2} \mathrm{O}(\mathrm{I})$.

\begin{tabular}{|c|c|c|c|c|c|c|c|}
\hline Atoms & & & Angle & Atoms & & & Angle \\
\hline $1^{\mathrm{i}}$ & $\mathrm{Ca} 1$ & $\mathrm{Ca} 1^{\mathrm{iii}}$ & $128.166(9)$ & $\mathrm{Ca} 1^{\mathrm{iii}}$ & O1_2 & $\mathrm{Ca} 1^{\mathrm{iv}}$ & $98.10(3)$ \\
\hline a1 & O1_1 & $\mathrm{Ca} 1^{i \mathrm{iii}}$ & 96.90 (2) & Ca $a^{\mathrm{iii}}$ & O2_2 & $\mathrm{Ca} 1$ & $4.54(2)$ \\
\hline 1_1 & $\mathrm{Ca} 1$ & O1_1 ${ }^{\mathrm{i}}$ & +1 & O1_2 $2^{i \mathrm{i}}$ & $\mathrm{Ca} 1$ & 3_2 & $.18(2)$ \\
\hline 1_1 & $\mathrm{Ca} 1$ & $\mathrm{O} 1 \_2^{\mathrm{i}}$ & 68.22 & ii & $\mathrm{Ca} 1$ & - & \\
\hline 11 & $\mathrm{Ca} 1$ & O1_2 $2^{\mathrm{ii}}$ & 2) & & $\mathrm{Ca} 1$ & $1 \_2^{\mathrm{ii}}$ & $78(2)$ \\
\hline 1. & $\mathrm{Ca}$ & $\mathrm{O} 2$ & & & $\mathrm{Ca}$ & $2 \_1$ & $28(2)$ \\
\hline 1 & $\mathrm{Ca} 1$ & & & & $\mathrm{Ca}$ & & \\
\hline 1_1 & $\mathrm{Ca}$ & & & i & $\mathrm{Ca}$ & $2^{i}$ & \\
\hline 1_1 & & & & & & & \\
\hline 11 & $\mathrm{Ca}$ & & & O1_2 & $\mathrm{Ca}$ & & $12.12(4)$ \\
\hline $1^{\mathrm{i}}$ & $\mathrm{Ca} 1$ & O1_2 $2^{\mathrm{i}}$ & & O2 1 & $\mathrm{Ca} 1$ & 2 & $121.08(2)$ \\
\hline & $\mathrm{Ca}$ & O1_2 $2^{\mathrm{ii}}$ & & & & $2 \_2^{i}$ & \\
\hline 1_1 $1^{\mathrm{i}}$ & C & & & & & 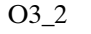 & \\
\hline $1^{\mathrm{i}}$ & $\mathrm{Ca} 1$ & O2_2 & ) & O2_1 & $\mathrm{Ca} 1$ & O4_2 & $126.29(2)$ \\
\hline O1_1 ${ }^{\mathrm{i}}$ & $\mathrm{Ca} 1$ & O3_2 & 3176 & O2_2 & $\mathrm{Ca} 1$ & O3_2 & 66.97 (2) \\
\hline O1_1 ${ }^{\mathrm{i}}$ & $\mathrm{Ca} 1$ & $\mathrm{O} 2 \_2^{\mathrm{i}}$ & & & $\mathrm{Ca} 1$ & & $67.79(2)$ \\
\hline & Ca1 & & & & $\mathrm{Ca}$ & $2 \_2$ & $132.35(2)$ \\
\hline & Ca1 & & & & $\mathrm{Ca}$ & & \\
\hline & $\mathrm{C}$ & & & $\mathrm{O} 2 \_2^{\mathrm{i}}$ & $\mathrm{Ca} 1$ & & 143 \\
\hline O1_2 $2^{\mathrm{ii}}$ & $\mathrm{Ca} 1$ & $\mathrm{O} 2 \_2^{\mathrm{i}}$ & $71.50(2)$ & O3_2 & $\mathrm{Ca} 1$ & O4_2 & $63.18(2)$ \\
\hline
\end{tabular}

Symmetry codes: (i) $x+\frac{1}{2}, \frac{1}{2}-y, 1-z$; (ii) $x+1, y, z$; (iii) $x-\frac{1}{2}, \frac{1}{2}-y, 1-z$; (iv) $x-1, y, z$.

2016), the asymmetric unit contains nine oxygen-atom-bridged calcium ions. In this case, the mean calcium-calcium distance is 3.62 (2) $\AA$, with the maximum being 3.647 (1) and the minimum being 3.595 (1) ^ (Nair et al., 2016). The coordination number for each calcium in this structure is eight.

Fig. 4 summarizes the number of CSD entries (as of November 2017) for calcium coordinated by any non-metal and by just oxygen. At the time of writing there were 62 entries with calcium coordinated by nine oxygen atoms. The maximum number of oxygen atoms coordinated to calcium was ten, for which there were eight entries.

Contrary to expectations, neither of the two crystallographically independent O6 hydroxy atoms of the calcium gluconate structure participate in calcium binding. Instead, both contribute to hydrogen bonding interactions that link adjacent polynuclear chains and the solvate waters together. One of the O6 atoms (O6_1) acts as the hydrogen donor in hydrogen bonding to the water molecule in the same asymmetric unit and as an acceptor in a bonding interaction with O3 (O3_1) of an adjacent Gluc1 gluconate. The second gluconate O6 atom (O6_2) acts as a hydrogen bond donor to the carboxylate $\mathrm{O}^{\prime}\left(\mathrm{O}^{\prime} \_2\right)$ of a symmetry-related Gluc2 gluconate and as an acceptor in a hydrogen bond with a nearby water molecule. Hydrogen bonding details are provided in Table S1 of the supporting information.
Of the oxygen atoms of gluconate Gluc1, all but the carboxylate oxygen $\mathrm{O} 1$ participate in interchain hydrogen bond interactions that, collectively, constitute a three-dimensional network (see Figs. S1 and S2 in the supporting information). The $\mathrm{O} 1^{\prime}$ oxygen of the same carboxylate acts as an acceptor in hydrogen bonding interactions with the O4 hydroxy group on a Gluc2 ligand in an adjoining asymmetric unit of the same chain and with the O5 hydroxy on a Gluc1 ligand in an adjacent chain. The Gluc1 O2 hydroxy group acts as a donor in a hydrogen bonding interaction with $\mathrm{O} 4$ of the same ligand (see discussion within) and $\mathrm{O} 6$ of a Gluc2 gluconate in an adjacent chain. The $\mathrm{O} 3$ hydroxy group of Gluc1 acts as an acceptor in a hydrogen bonding interaction with the $\mathrm{O} 2$ (O2_2) hydroxy group of an adjacent Gluc2 gluconate in an adjoining asymmetric unit of the same chain. The same Gluc1 $\mathrm{O} 3$ hydroxy also acts as a donor in an interaction with the $\mathrm{O} 6$ oxygen of a Gluc1 ligand in an adjacent chain. The O4 hydroxy of Gluc1 participates in three hydrogen bond interactions. In one of these interactions, the group serves as a donor to the O1' carboxylate of a Gluc1 ligand in an adjoining asymmetric unit of the same chain. The Gluc1 O4 oxygen also acts as an acceptor for the $\mathrm{O} 2$ hydroxy of the same ligand and the O5 hydroxy of a Gluc2 gluconate on an adjacent chain. In contrast, the O5 hydroxy of Gluc1 participates in only one hydrogen bond interaction, acting as a donor to the $\mathrm{O}^{\prime}$ carboxylate oxygen of a Gluc1 ligand on an adjacent chain.

In a similar way to that of gluconate Gluc1, only the O1 carboxylate oxygen of the six oxygen atoms of Gluc2 does not participate in interchain hydrogen bond interactions. The second carboxylate of this ligand, $\mathrm{O}^{\prime}$ of Gluc2 (O1'_2), acts as an acceptor for the O6 hydroxy group on an adjacent chain. In addition to bridging between the calcium ion of the asymmetric unit and that of an adjacent asymmetric unit, the $\mathrm{O} 2$ hydroxy of Gluc2 serves as a donor to the O3 oxygen of a Gluc1 gluconate in an adjoining asymmetric unit of the same chain. In addition to coordinating with the calcium ion, the $\mathrm{O} 3$ hydroxy group of Gluc2 acts as a donor in an interaction with a water molecule. The $\mathrm{O} 4$ hydroxy of the Gluc2 ligand is also metal-bound and additionally acts as a donor to the carboxylate $\mathrm{O} 1^{\prime}$ oxygen of a Gluc1 gluconate in an adjoining

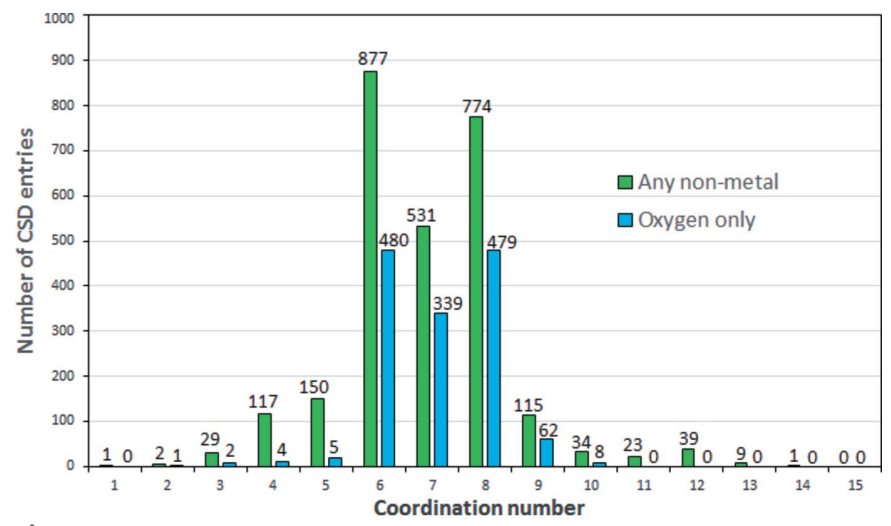

Figure 4

Graphical representation of calcium ion coordination statistics from the Cambridge Structural Database (CSD) (Groom et al., 2016), as of November 2017. 
asymmetric unit of the same chain. The O5 hydroxy of the Gluc2 ligand serves as a donor to the O4 oxygen of a Gluc1 gluconate on an adjacent chain and as an acceptor for a water molecule.

The crystallographically unique water molecule acts as an acceptor in two hydrogen bonds, with one involving $\mathrm{O} 3$ (O3_2) of the second unique gluconate of the asymmetric unit, Gluc2, and the other being O6 (O6_1) of a symmetry-related Gluc1 gluconate on an adjacent polynuclear chain. The water molecule also acts as a donor for two hydrogen bonds, with one involving O6 (O6_2) of a gluconate in an adjacent chain and O5 (O5_2) of another gluconate in the same adjacent chain. The water molecule thus interacts with three polynuclear chains.

The carbon atoms of the two crystallographically independent gluconates are approximately coplanar, with leastsquares plane deviations ranging from 0.031 (1) to 0.140 (1) $\AA$ for Gluc1 and 0.047 (1) to 0.211 (1) $\AA$ for Gluc2. Notwithstanding these deviations from coplanarity, neither gluconate has the 'bent' gluconate conformation found in the gluconic acid monohydrate crystal structure (Lis, 1983), the ammonium gluconate crystal structure (Lis, 1981) and in the monoclinic dimorph of potassium gluconate monohydrate (Jeffrey \& Fasiska, 1972). In contrast to the monoclinic dimorph, the 'backbone' carbon atoms of the ligand in the orthorhombic second potassium gluconate monohydrate dimorph are, similarly to those of the calcium gluconate monohydrate structure reported here, essentially coplanar. This is also the case for the crystal structures reported for the lead (Lis, 1984a) and sodium (Lis, 1984b) gluconate complexes. Of note, the gluconate carbon chain atoms of the lead structure are coplanar to within $0.6 \AA$.

The gluconate 'bend' in both the gluconic acid monohydrate crystal structure and in the ammonium gluconate crystal structure arises from a rotation round the $\mathrm{C} 2-\mathrm{C} 3$ bond, forming $\mathrm{C} 1-\mathrm{C} 2-\mathrm{C} 3-\mathrm{C} 4$ torsion angles of -71.3 and $-54.4^{\circ}$, respectively. In contrast, the conformation of the gluconate in the bent ligand potassium gluconate monohydrate dimorph arises from rotation around two bonds, such that the ligand has $\mathrm{C} 2-\mathrm{C} 3-\mathrm{C} 4-\mathrm{C} 5$ and $\mathrm{C} 3-\mathrm{C} 4-\mathrm{C} 5-\mathrm{C} 6$ torsion angles of 54.2 and $50.7^{\circ}$, respectively.

In discussing the differences between the planar and the bent gluconate dimorphs found in the crystal structures of potassium gluconate monohydrate, referred to as the A and B forms, respectively, Panagiotopoulos et al. (1974) associate the adoption of a planar gluconate conformation with the presence of an intramolecular hydrogen bond between the hydroxy group on $\mathrm{C} 2$ and that on C4 and, additionally, a 1,3syn disposition of these groups. This interaction and disposition are both absent in the bent ligand dimorph of potassium gluconate monohydrate and nor are they found in the bent gluconate anion of the ammonium gluconate salt crystal structure (Lis, 1981) or in the bent acid molecule of the gluconic acid monohydrate crystal structure (Lis, 1983).

The dichotomy suggested by the $\mathrm{A}$ and $\mathrm{B}$ dimorphs of potassium gluconate monohydrate is broken by the Gluc2 ligand in the calcium gluconate monohydrate structure. With a maximum least-squares plane deviation of 0.211 (1) $\AA$, the carbon atoms of this ligand are approximately coplanar and the ligand has $\mathrm{C} 1-\mathrm{C} 2-\mathrm{C} 3-\mathrm{C} 4, \mathrm{C} 2-\mathrm{C} 3-\mathrm{C} 4-\mathrm{C} 5$ and $\mathrm{C} 3-$ C4-C5-C6 torsion angles of $-178.46(7), 160.70$ (7) and $-172.67(8)^{\circ}$, respectively. The corresponding angles of the Gluc1 ligand, with the somewhat smaller 0.140 (1) $\AA$ maximum least-squares plane deviation, are similar in being -177.73 (7), 165.25 (8) and $-176.44(8)^{\circ}$. Yet while both have very similar, approximately planar, conformations and both have a 1,3-syn disposition of the hydroxy group on $\mathrm{C} 4$ with respect to that on $\mathrm{C} 2$, the Gluc2 gluconate does not have an intramolecular hydrogen bond.

Both the crystal structure of the calcium gluconate monohydrate and that of the A form of the potassium gluconate monohydrate have non-centrosymmetric $P 2_{1} 2_{1} 2_{1}$ orthorhombic symmetry. Both comprise one-dimensional coordination polymers parallel to the $a$ axis (in the settings used), both have three $\mu$-oxo bridges spanning adjacent metal centres and both have essentially planar gluconate backbones. They are not, however, isostructural and there are noteworthy differences. The three bridging oxygen atoms in the calcium structure are provided by three gluconate ligands, in contrast to two gluconate ligands and one water molecule providing the bridging oxygen atoms in the potassium structure. Although the asymmetric units of both structures contain a water molecule, the molecule is not coordinated to the metal in the calcium structure, whereas it is in the potassium structure. The two structures also have quite different hydrogen-bond networks. Unlike the carboxylates of the other metal gluconate structures, the carboxylate moiety of the potassium gluconate structure does not coordinate with the cation.

The O1, O2, C1 and C2 atoms of the Gluc1 ligand of the calcium structure are coplanar, with the maximum deviation of $0.054 \AA$ from the least-squares plane for $\mathrm{C} 1$. The calcium ion is 0.458 (2) $\AA$ from this 'coordination' plane, whereas $\mathrm{O}^{\prime}$ ' is 0.182 (2) $\AA$ from this plane. The carboxylate O1 and hydroxy $\mathrm{O} 2$ of the Gluc2 ligand do not participate in binding the calcium of the same asymmetric unit. Instead the $\mathrm{O} 2, \mathrm{O} 3$ and $\mathrm{O} 4$ of this second crystallographically unique gluconate coordinate to the calcium, with the calcium being 1.937 (1) $\AA$ from the plane defined by the three hydroxy oxygen atoms. The calcium is, however, coordinated by the carboxylate $\mathrm{O} 1$ and hydroxy $\mathrm{O} 2$ of a screw-axis-related Gluc2 ligand. The carboxylate $\mathrm{O} 1, \mathrm{O} 2, \mathrm{C} 1$ and $\mathrm{C} 2$ atoms of this ligand are essentially coplanar, with the largest deviation from the leastsquares plane being 0.106 (1) $\AA$ for $\mathrm{C} 2$. The calcium deviation from this plane is just 0.020 (2) $\AA$. The dihedral angle formed by the two calcium coordination planes is $63.65(6)^{\circ}$.

The largest deviation from the least-squares plane for the O1, O1', C1 and C2 atoms of Gluc, is that of C1 at 0.011 (1) A. The calcium ion is 0.756 (2) $\AA$ from this plane, whereas O2 is 0.227 (2) $\AA$ from that plane. Norrestam et al. (1968) noted that the proximity of the hydroxy oxygen $\mathrm{O} 2$ to this plane appears to be a common feature of $\alpha$-hydroxycarboxylic ions and acids, and is probably not the result of metal coordination. At 0.460 (2) $\AA$ the distance of the hydroxy oxygen $\mathrm{O} 2$ of the Gluc2 ligand from the corresponding plane of that ligand is a 
Table 4

Selected distances $(\AA)$ for the $[\mathrm{CaGluc}]^{+}$complexes calculated at the B3LYP level applying the $6-311++\mathrm{g}(\mathrm{d}, \mathrm{p})$ basis set.

The numbering is seen on Fig. 5. $D$ is donor oxygen, $\mathrm{H}$ is hydrogen, $A$ is acceptor oxygen.

\begin{tabular}{|c|c|c|c|c|c|c|c|}
\hline \multicolumn{3}{|c|}{$\mathrm{Ca}-\mathrm{O}$ distances } & \multicolumn{5}{|c|}{ Hydrogen bond distances } \\
\hline Ato & & $\mathrm{Ca}-\mathrm{O}$ & $D$ & $\mathrm{H}$ & A & $D-\mathrm{H}$ & $\mathrm{H} \cdots A$ \\
\hline \multicolumn{8}{|c|}{ Complex_1 } \\
\hline $\mathrm{Ca}$ & $\mathrm{O} 1$ & 2.384 & $\mathrm{O} 3$ & $\mathrm{H}(\mathrm{O} 3)$ & O5 & 0.976 & 1.822 \\
\hline $\mathrm{Ca}$ & O3 & 2.475 & $\mathrm{O} 4$ & $\mathrm{H}(\mathrm{O} 4)$ & $\mathrm{O} 2$ & 0.970 & 1.923 \\
\hline $\mathrm{Ca}$ & $\mathrm{O} 1 W$ & 2.442 & O5 & $\mathrm{H}(\mathrm{O} 5)$ & O6 & 0.968 & 2.185 \\
\hline $\mathrm{Ca}$ & $\mathrm{O} 2 W$ & 2.424 & $\mathrm{O} 1 W$ & $\mathrm{H}(\mathrm{O} 1 W)$ & O1 & 0.970 & 2.079 \\
\hline $\mathrm{Ca}$ & $\mathrm{O} 3 W$ & 2.412 & $\mathrm{O} 4 W$ & $\mathrm{H}(\mathrm{O} 4 W)$ & $\mathrm{O} 4$ & 0.979 & 1.895 \\
\hline $\mathrm{Ca}$ & $\mathrm{O} 4 W$ & 2.464 & $\mathrm{O} 3 W$ & $\mathrm{H}(\mathrm{O} 3 W)$ & $\mathrm{O} 4 W$ & 0.965 & $2.598 \dagger$ \\
\hline \multicolumn{8}{|c|}{ Complex_2 } \\
\hline $\mathrm{Ca}$ & $\mathrm{O} 1$ & 2.313 & $\mathrm{O} 3$ & $\mathrm{H}(\mathrm{O} 3)$ & $\mathrm{O} 1^{\prime}$ & 0.983 & 1.766 \\
\hline $\mathrm{Ca}$ & $\mathrm{O} 2$ & 2.465 & $\mathrm{O} 4$ & $\mathrm{H}(\mathrm{O} 4)$ & O5 & 0.969 & 2.047 \\
\hline $\mathrm{Ca}$ & $\mathrm{O} 1 W$ & 2.443 & O5 & $\mathrm{H}(\mathrm{O} 5)$ & O6 & 0.964 & $2.549 \dagger$ \\
\hline $\mathrm{Ca}$ & $\mathrm{O} 2 W$ & 2.431 & $\mathrm{O} 3 W$ & $\mathrm{H}(\mathrm{O} 3 W)$ & $\mathrm{O} 4$ & 0.983 & 1.748 \\
\hline $\mathrm{Ca}$ & $\mathrm{O} 3 W$ & 2.402 & & & & & \\
\hline $\mathrm{Ca}$ & $\mathrm{O} 4 W$ & 2.430 & & & & & \\
\hline
\end{tabular}

$\dagger$ The value of the distance $D-\mathrm{H} \cdots A$ is used to assess the significance of hydrogen bonds.

little larger than the 0.227 (2) $\AA$ found for the Gluc1 ligand. Of note, the carboxylate $\mathrm{O} 1$ of Glu2 is not coordinated to the metal in the asymmetric unit. The bridging role of the $\mathrm{O} 2$ of Gluc2 may be responsible for its marginally larger displacement from the carboxylate plane of the second ligand.

\subsection{Molecular modelling of the structure of $[\mathrm{CaGluc}]^{+}$in water}

NMR studies of ${ }^{1} \mathrm{H}-{ }^{43} \mathrm{Ca}$ interactions suggest (Pallagi et al., 2010) that, in addition to the carboxylate group, the primary metal binding sites of $\mathrm{Gluc}^{-}$are the $\mathrm{C} 2-\mathrm{OH}$ and $\mathrm{C} 3-\mathrm{OH}$ groups

In the continuum of implicit solvent molecules model, the most stable structure has the $\mathrm{Ca}^{2+}$ coordinated by the $\mathrm{O} 1, \mathrm{O} 2$ and $\mathrm{O} 3 \mathrm{O}$ atoms, in accord with previous results (Tajmir-Riahi, 1990; Pallagi et al., 2010). In exploring additional coordination, it was found that the additional participation of either the $\mathrm{C} 4-\mathrm{OH}$ or the $\mathrm{C} 6-\mathrm{OH}$ group imposed significantly higher energy $\left(28.7 \mathrm{~kJ} \mathrm{~mol}^{-1}\right.$ for $\mathrm{C} 4-\mathrm{OH}$ and $32.1 \mathrm{~kJ} \mathrm{~mol}^{-1}$ for $\mathrm{C} 6-$ $\mathrm{OH})$. Of note, the modelling finds that the carboxylate anchor acts as a monodentate ligand in the aqueous phase, in agreement with the single-crystal structure (Fig. 3) and with previous results of the infrared analysis of solid $\mathrm{CaGluc}_{2}$ (Tajmir-Riahi, 1990).

Surprisingly, given the coordination motifs found in the crystal structure, the $\mathrm{Ca}-\mathrm{O} 2$ interaction becomes unfavourable on introducing four $\mathrm{H}_{2} \mathrm{O}$ molecules into the model structure. The lowest-energy structure [complex 1, shown in Fig. 5(a)] has the metal ion bound to water molecules as well as to the carboxylate and $\mathrm{C} 3-\mathrm{OH}$ groups (i.e. $\mathrm{CN}$ 6). The respective bond lengths (Table 4 ) range from 2.384 to $2.475 \AA$. These results are in good agreement with those reported in the literature. That is, bond distances for aqueous $\mathrm{CaCl}_{2}$ solutions were found to be between 2.39 and $2.46 \AA$, depending on the experimental method [XRD (Bol et al., 1970; Albright, 1972; Probst et al., 1985; Megyes et al., 2004), ND (Cummings et al., 1980; Hewish et al., 1982; Badyal et al., 2004; Megyes et al., 2006), EXAFS (Spangberg et al., 2000; Tongraar et al., 2010)] applied. On the other hand, $2.37 \AA$ was calculated for infinite dilution via MD simulations (Di Tommaso et al., 2014). Based on these data, the $\mathrm{Ca} \cdots \mathrm{O} 2$ distance $(2.60 \AA)$ is on the edge of being considered as a realistic interaction.

The $\mathrm{Ca}-\mathrm{O} 3$ distance $(2.48 \AA)$ is slightly larger than that found for the solid state [2.4123 (7) $\AA$, Table 2]. The most noticeable difference is that the $\mathrm{Ca}-\mathrm{O}$ (carboxylate) lengths are larger by approximately 0.1 to $0.2 \AA$ in the crystal structure, suggesting stronger carboxylate coordination in the aqueous complex.

In the second lowest-energy structure, $\mathrm{Ca}^{2+}$ binds to the $\mathrm{COO}^{-}$and $\mathrm{C} 2-\mathrm{OH}$ groups [complex 2, shown in Fig. 5(b)]. The free energy of this isomer is $3.4 \mathrm{~kJ} \mathrm{~mol}^{-1}$ higher than that of complex 1 ; this difference is not significant since the energy

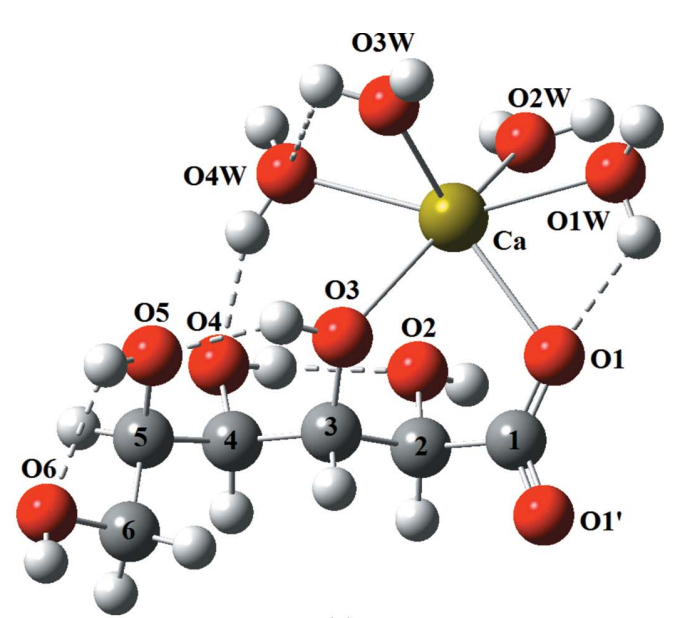

(a)

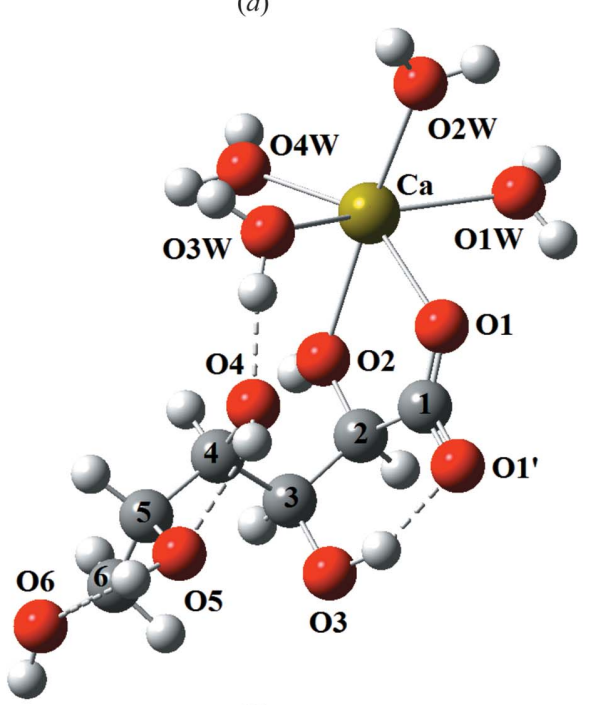

(b)

Figure 5

Optimized model structures complex $1(a)$ and complex $2(b)$ for aqueous $[\mathrm{CaGluc}]^{+}$. The calculations were performed at B3LYP level applying the $6-311++g(d, p)$ basis set. Solvent effects were taken into account utilizing the PCM model. Solid or dashed lines represent the $\mathrm{Ca}-\mathrm{O}$ interactions or the hydrogen bonds, respectively. 
Table 5

Selected distances ( $\mathrm{A})$ for $\mathrm{CaIsa}_{2}$ (II).

\begin{tabular}{llllll}
\hline Atoms & & Distance & Atoms & & Distance \\
\hline $\mathrm{Ca} 1$ & $\mathrm{O}^{\text {i }}$ & $2.382(2)$ & $\mathrm{Ca} 1$ & $\mathrm{O} 1^{\mathrm{ii}}$ & $2.382(2)$ \\
$\mathrm{Ca} 1$ & $\mathrm{O}^{\mathrm{iii}}$ & $2.383(2)$ & $\mathrm{Ca} 1$ & $\mathrm{O} 5$ & $2.383(2)$ \\
$\mathrm{Ca} 1$ & $\mathrm{O}^{\text {ii }}$ & $2.435(2)$ & $\mathrm{Ca} 1$ & $\mathrm{O} 2^{\mathrm{i}}$ & $2.435(2)$ \\
$\mathrm{Ca} 1$ & $\mathrm{O}^{\text {iii }}$ & $2.512(2)$ & $\mathrm{Ca} 1$ & $\mathrm{O} 4$ & $2.512(2)$ \\
\hline
\end{tabular}

Symmetry codes: (i) $1-x,-y,+z$; (ii) $x-1, y, z$; (iii) $-x,-y, z$.

of thermal motion is $2.48 \mathrm{~kJ} \mathrm{~mol}^{-1}$ at $298.15 \mathrm{~K}$. The $\mathrm{Ca}-\mathrm{O} 1$ and $\mathrm{Ca}-\mathrm{O} 2$ distances are similar to the metal-oxygen distances of complex 1 , at $2.31 \AA$ and $2.47 \AA$, respectively.

The likelihood of (at least) two linkage isomers in solution is in agreement with previous experimental and computational studies undertaken by Pallagi et al. (2010), who have proposed that these complexes are in dynamic equilibrium.

Strong hydroxy to hydroxy and hydroxy to water hydrogen bonds (Table 4) are found in both complexes. Additionally, a hydrogen bond is formed between the $\mathrm{COO}^{-}$and $\mathrm{H}(\mathrm{O} 3)$ moieties of complex 2. Numerous examples of the affinity of $\mathrm{COO}^{-}$for hydrogen bond interactions are known in the literature (Panagiotopoulos et al., 1974).

\subsection{Structural characterization of calcium(II) $a$-D-isosac- charinate}

Though obtaining single crystals of $\mathrm{Ca}$ isosaccharinate suitable for X-ray diffraction analysis is problematic, the crystal structure of calcium $\alpha$-D-glucoisosaccharate was reported in 1968 (Norrestam et al., 1968). Using a conventional laboratory instrument, weak diffraction from the small specimen limited the resolution of the structure to $0.97 \AA$ and precluded the use of anisotropic displacement parameters for all but the calcium ion. The data did not allow the location of the hydroxy hydrogen sites. The use of a synchrotron source as part of the work being reported here provided data of sufficient quality to allow both the use of anisotropic displacement parameters for all of the non-hydrogen atoms and the location

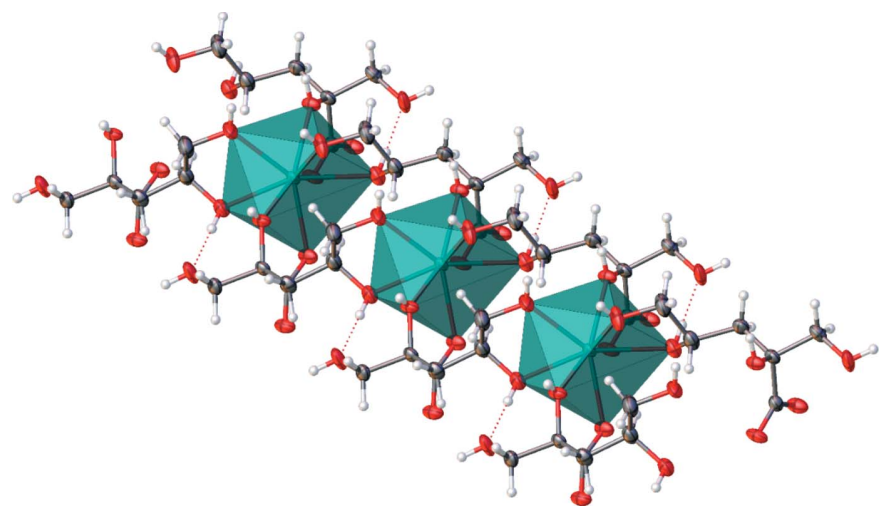

Figure 6

Trinuclear segment of a coordination polymer in the single-crystal structure of $\mathrm{CaIsa}_{2}$ at $100 \mathrm{~K}$, showing the distorted Archimedean antiprisms defined by the oxygen coordination of the calcium ions. In contrast to the gluconate structure, there are no $\mu$-oxo bridge bridges and the metal to metal distance is that of the length of the $a$ axis, 6.7573 (4) $\AA$.
Table 6

Selected bond angles $\left(^{\circ}\right)$ for $\mathrm{CaIsa}_{2}$ (II).

\begin{tabular}{|c|c|c|c|c|c|c|c|}
\hline \multicolumn{3}{|c|}{ Atoms } & \multirow{2}{*}{$\begin{array}{l}\text { Angle } \\
86.7(1)\end{array}$} & \multicolumn{3}{|c|}{ Atoms } & \multirow{2}{*}{$\begin{array}{l}\text { Angle } \\
111.90(6)\end{array}$} \\
\hline $\mathrm{O} 1^{\mathrm{i}}$ & $\mathrm{Ca} 1$ & $\mathrm{O} 1^{\mathrm{ii}}$ & & $\mathrm{O} 2^{\mathrm{i}}$ & $\mathrm{Ca} 1$ & $\mathrm{O} 4^{\mathrm{iii}}$ & \\
\hline $\mathrm{O} 1^{\mathrm{i}}$ & Ca1 & $\mathrm{O} 2^{\mathrm{i}}$ & $64.97(7)$ & $\mathrm{O} 2^{\mathrm{i}}$ & Ca1 & $\mathrm{O} 4$ & $76.71(6)$ \\
\hline $\mathrm{O} 1^{\mathrm{i}}$ & $\mathrm{Ca} 1$ & $\mathrm{O} 2^{\mathrm{ii}}$ & $146.76(7)$ & $\mathrm{O} 2^{\mathrm{i}}$ & Ca1 & $\mathrm{O} 5^{\mathrm{iii}}$ & $72.66(7)$ \\
\hline $\mathrm{O} 1^{\mathrm{i}}$ & $\mathrm{Ca} 1$ & $\mathrm{O} 4$ & $78.06(7)$ & $\mathrm{O} 2^{\mathrm{i}}$ & Ca1 & O5 & $82.84(7)$ \\
\hline $\mathrm{O} 1^{\mathrm{i}}$ & $\mathrm{Ca} 1$ & $\mathrm{O} 4^{\mathrm{iii}}$ & $80.84(7)$ & $\mathrm{O} 2^{\mathrm{ii}}$ & $\mathrm{Ca} 1$ & $\mathrm{O} 4$ & $111.90(6)$ \\
\hline $\mathrm{O} 1^{\mathrm{i}}$ & $\mathrm{Ca} 1$ & O5 & $137.08(6)$ & $\mathrm{O} 2^{\mathrm{ii}}$ & $\mathrm{Ca} 1$ & $\mathrm{O} 4^{\mathrm{iii}}$ & $76.71(6)$ \\
\hline $\mathrm{O} 1^{\mathrm{i}}$ & $\mathrm{Ca} 1$ & $\mathrm{O} 5^{\mathrm{iii}}$ & 7) & $\mathrm{O} 2^{\mathrm{ii}}$ & Ca1 & $\mathrm{O} 5^{\mathrm{iii}}$ & $82.84(7)$ \\
\hline $\mathrm{O} 1^{\mathrm{ii}}$ & $\mathrm{Ca} 1$ & $\mathrm{O} 2^{\mathrm{ii}}$ & $64.97(7)$ & $\mathrm{O} 2^{\mathrm{ii}}$ & $\mathrm{Ca} 1$ & $\mathrm{O} 5$ & $72.66(7)$ \\
\hline $\mathrm{O} 1^{\mathrm{ii}}$ & $\mathrm{Ca} 1$ & $\mathrm{O} 4$ & $80.84(7)$ & $\mathrm{O} 4$ & $\mathrm{Ca} 1$ & $\mathrm{O} 4^{\mathrm{iii}}$ & $150.8(1)$ \\
\hline $\mathrm{O} 1^{\mathrm{ii}}$ & $\mathrm{Ca} 1$ & $\mathrm{O} 4^{\mathrm{iii}}$ & $78.06(7)$ & $\mathrm{O} 4$ & Ca1 & O5 & $67.00(7)$ \\
\hline $\mathrm{O} 1^{\mathrm{ii}}$ & $\mathrm{Ca} 1$ & O5 & $110.44(7)$ & $\mathrm{O} 4$ & $\mathrm{Ca} 1$ & $\mathrm{O} 5^{\mathrm{iii}}$ & $139.92(7)$ \\
\hline $\mathrm{O} 1^{\mathrm{ii}}$ & $\mathrm{Ca} 1$ & $\mathrm{O} 5^{\mathrm{iii}}$ & $137.08(6)$ & O5 & $\mathrm{Ca} 1$ & $\mathrm{O} 5^{\mathrm{iii}}$ & 83.9 (1) \\
\hline $\mathrm{O} 2^{\mathrm{i}}$ & $\mathrm{Ca} 1$ & $\mathrm{O} 2^{\mathrm{ii}}$ & 147.0 (1) & & & & \\
\hline
\end{tabular}

Symmetry codes: (i) $1-x,-y, z$; (ii) $x-1, y, z$; (iii) $-x,-y, z$.

of the electron density associated with the hydroxy hydrogen sites.

The asymmetric unit of the calcium $\alpha$-D-isosaccharinate complex contains half of a $\left[\mathrm{CaIsa}_{2}\right]^{0}$ complex, with the metal ion located on the twofold axis of $P 22_{1} 2_{1} 2$. As Norrestam et al. (1968) observed, bound by eight metal oxygen atoms (see Fig. S6 in the supporting information) the coordination polyhedron of the $\left[\mathrm{CaIsa}_{2}\right]^{0}$ crystal structure is that of a distorted Archimedean antiprism (see Fig. 6).

While the 1968 structure report does not discuss the metalbinding motif, Fig. 7 (also see Fig. S7 in the supporting information) exposes dexterity not found in the solution and computational studies. Underpinning the coordination polymer, in the single-crystal structure the ligand binds two calcium ions, with one metal bound to carboxylate oxygen $\mathrm{O} 1$ and hydroxy $\mathrm{O} 2$, and the second bound to hydroxyl $\mathrm{O}$ atoms $\mathrm{O} 4$ and O5. Hydroxyl oxygen $\mathrm{O} 6$ and carboxylate $\mathrm{O} 1^{\prime}$ do not participate in metal binding. In contrast, the computational

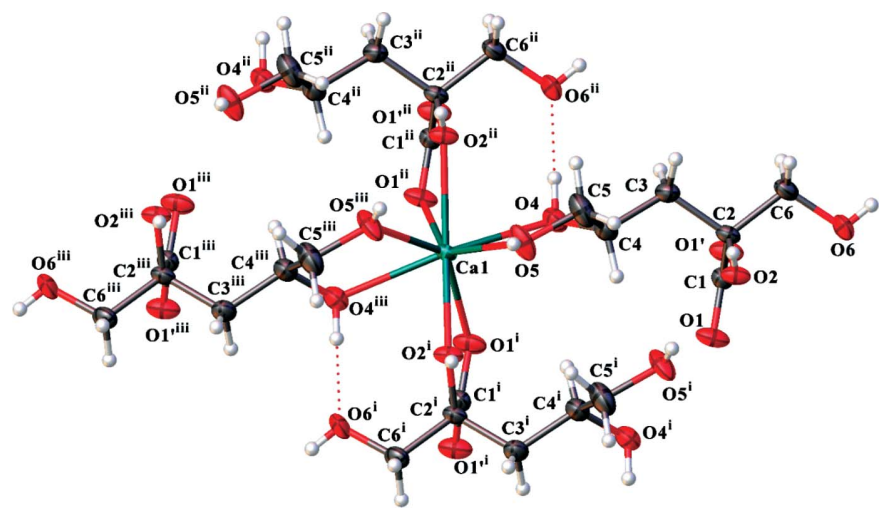

Figure 7

The single-crystal structure of $\mathrm{CaIsa}_{2}$ at $100 \mathrm{~K}$ with displacement ellipsoids shown at the $90 \%$ level. The metal is located on a twofold axis and in the figure the asymmetric unit component of the structure is shown on the right-hand side (no Roman numeral superscripts; see also Fig S7 in the supporting information), while that related by the twofold axis is shown on the left (denoted with superscript iii). The coordination sphere is completed by oxygen atoms from ligands of adjacent coordination polymers. Symmetry codes: (i) $1-x,-y, z$; (ii) $x-1, y$, $z$; (iii) $-x,-y, z$. 
Table 7

Selected bond lengths $(\AA)$ for the model $[\mathrm{CaIsa}]^{+}$complex calculated at the B3LYP level applying the $6-311++\mathrm{g}(\mathrm{d}$,p) basis set.

The numbering is shown in Fig. 8. $D$ is donor oxygen, $\mathrm{H}$ is hydrogen on donor oxygen, $A$ is acceptor oxygen.

\begin{tabular}{|c|c|c|c|c|c|c|c|}
\hline \multicolumn{3}{|c|}{$\mathrm{Ca}-\mathrm{O}$ distances } & \multicolumn{5}{|c|}{ Hydrogen bond distances } \\
\hline \multicolumn{2}{|c|}{ Atoms } & $\mathrm{Ca}-\mathrm{O}$ & $D$ & $\mathrm{H}$ & $A$ & $D-\mathrm{H}$ & $\mathrm{H} \cdots A$ \\
\hline \multicolumn{8}{|c|}{ Complex 3} \\
\hline $\mathrm{Ca}$ & $\mathrm{O} 1$ & 2.375 & $\mathrm{O} 4$ & $\mathrm{H}(\mathrm{O} 4)$ & $\mathrm{O} 1^{\prime}$ & 0.979 & 1.780 \\
\hline $\mathrm{Ca}$ & $\mathrm{O} 2$ & 2.501 & O5 & $\mathrm{H}(\mathrm{O} 5)$ & $\mathrm{O} 4$ & 0.966 & 2.255 \\
\hline $\mathrm{Ca}$ & O6 & 2.457 & $\mathrm{O} 1 W$ & $\mathrm{H}(\mathrm{O} 1 W)$ & O1 & 0.969 & 2.137 \\
\hline $\mathrm{Ca}$ & $\mathrm{O} 1 W$ & 2.463 & & & & & \\
\hline $\mathrm{Ca}$ & $\mathrm{O} 2 W$ & 2.420 & & & & & \\
\hline $\mathrm{Ca}$ & $\mathrm{O} 3 W$ & 2.415 & & & & & \\
\hline $\mathrm{Ca}$ & $\mathrm{O} 4 W$ & 2.455 & & & & & \\
\hline \multicolumn{8}{|c|}{ Complex 4} \\
\hline $\mathrm{Ca}$ & O1 & 2.297 & $\mathrm{O} 2$ & $\mathrm{H}(\mathrm{O} 2)$ & O1' & 0.976 & 1.895 \\
\hline $\mathrm{Ca}$ & $\mathrm{O} 4$ & 2.444 & $\mathrm{O} 4$ & $\mathrm{H}(\mathrm{O} 4)$ & $\mathrm{O} 1 W$ & 0.970 & 2.333 \\
\hline $\mathrm{Ca}$ & O6 & 2.467 & $\mathrm{O} 4$ & $\mathrm{H}(\mathrm{O} 4)$ & O5 & 0.970 & 2.151 \\
\hline $\mathrm{Ca}$ & $\mathrm{O} 1 W$ & 2.541 & & & & & \\
\hline $\mathrm{Ca}$ & $\mathrm{O} 2 W$ & 2.445 & & & & & \\
\hline $\mathrm{Ca}$ & $\mathrm{O} 3 W$ & 2.530 & & & & & \\
\hline $\mathrm{Ca}$ & $\mathrm{O} 4 W$ & 2.487 & & & & & \\
\hline
\end{tabular}

studies (\$3.4) suggest that in aqueous solutions the $\mathrm{Isa}^{-}$ligand binds calcium using either the oxy triad O1-O4-O6 or that of O1-O2-O6.

The crystal structure is again orthorhombic and noncentrosymmetric, though in this case the symmetry is $P 2{ }_{1} 2{ }_{1} 2$. The structure again comprises coordination polymers aligned with the $a$ axis of the cell setting used for the structure (see Figs. S8 and S9 in the supporting information). The structure is notably distinguished from that of the gluconate by the absence of $\mu$-oxo bridging across the metal centres. Reflecting this, separated by the length of the $a$ axis [6.7573 (4) $\AA$ ], the intrachain calcium-calcium distance is much longer than the 3.7312 (2) $\AA$ found in the gluconate structure. Selected geometry details are given in Tables 5 and 6 .

While hydroxy oxygen $\mathrm{O} 4$ participates in an intrachain hydrogen bonding interaction, the rest of the oxygen atoms participates in interchain hydrogen-bond interactions establishing a three-dimensional network (see Figs. S8 and S9). Hydrogen bonding details are provided in Table S2 in the supporting information.

The isosaccharinate 'backbone atoms' C2, C3, C4 and C6 are coplanar, with the largest deviation from their leastsquares plane being 0.087 (4) $\AA$ for C6. The deviations of atoms $\mathrm{O} 6, \mathrm{O} 1, \mathrm{O} 2, \mathrm{O} 4$ and $\mathrm{O} 5$ from this plane are $0.086(5)$, 1.27 (1), 1.043 (6), 1.041 (5) and 1.365 (5) ̊, respectively. The $\mathrm{O} 1, \mathrm{O}^{\prime}, \mathrm{C} 1$ and $\mathrm{C} 2$ sites are coplanar with the largest leastsquares plane deviation being 0.007 (3) $\AA$ for $\mathrm{C} 1$. The calcium ion is 0.704 (4) $\AA$ from this plane, while $\mathrm{O} 2$ is 0.288 (4) $\AA$ [Norrestam et al. (1968) reported $0.3 \AA$ ] from this plane.

The $\mathrm{O} 1, \mathrm{O} 2, \mathrm{C} 1$ and $\mathrm{C} 2$ sites are coplanar with the largest deviation being 0.073 (3) $\AA$ for C1; the metal ion is 0.340 (5) $\AA$ from this 'coordination plane'. The dihedral angle formed between this plane and its twofold rotation related trans counterpart is $16.7(1)^{\circ}$. The distance of atoms $\mathrm{O} 4, \mathrm{O} 5, \mathrm{C} 4$ and $\mathrm{C} 5$ from their least-squares plane ranges from 0.077 (3) to
0.342 (4) $\AA$; calcium is 0.130 (6) $\AA$ from this plane. The dihedral angle formed between this plane and its twofold rotation related trans counterpart is $32.9(1)^{\circ}$.

\subsection{Molecular modelling of the structure of [Calsa ${ }^{+}$in water}

Previous studies suggested the most stable $[\mathrm{CaIsa}]^{+}$metalbinding motif would involve the $\mathrm{O} 1, \mathrm{O} 4$, and $\mathrm{O} 6$ atoms of the isosaccharinate ligand, with this variant having the lowest energy in the framework of implicit solvent molecules model (Dudás et al., 2017). Binding by the $\mathrm{COO}^{-}, \mathrm{C} 2-\mathrm{OH}$ and $\mathrm{C} 6-$ $\mathrm{OH}$ groups becomes preferred, however, if $\mathrm{H}_{2} \mathrm{O}$ molecules are explicitly included in the $\mathrm{Ca}^{2+}$ coordination shell. The optimized structures (complexes 3 and 4) are shown in Fig. 8. From the point of view of thermodynamic stability, the free energy of complex 3 is smaller by $7.2 \mathrm{~kJ} \mathrm{~mol}^{-1}$ than that of complex 4 . It should be noted that any other coordination mode results in considerably lower stability, including those with bidentate carboxylate coordination of the metal.
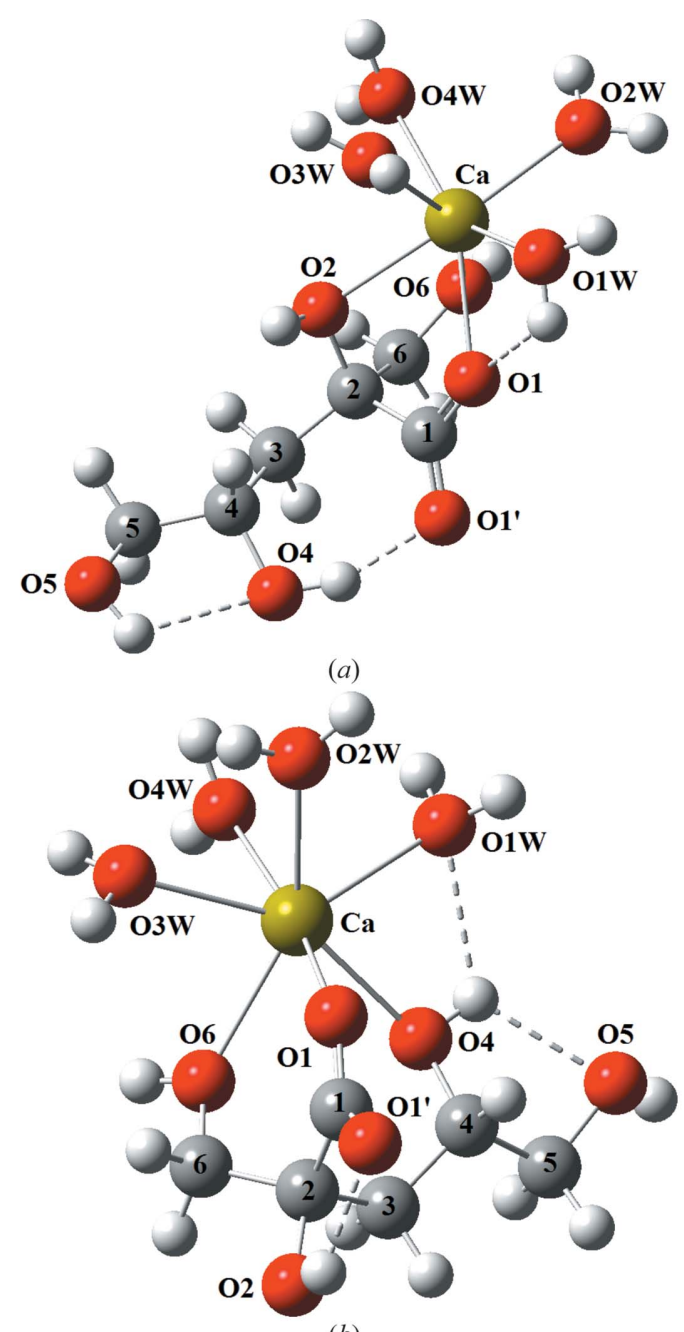

(b)

Figure 8

Optimized model structures complex $3(a)$ and complex $4(b)$ for aqueous $[\mathrm{CaIsa}]^{+}$. The calculations were performed at B3LYP level applying the $6-311++g(d, p)$ basis set. Solvent effects were taken into account utilizing the PCM model. Solid lines represent $\mathrm{Ca}-\mathrm{O}$ interactions, while dashed lines symbolize hydrogen bonds. 
In contrast to $\mathrm{Gluc}^{-}$, the modelling suggests that in aqueous solutions $\mathrm{Isa}^{-}$is able to optionally utilize two oxy triads (O1O4-O6 and O1-O2-O6) to accommodate the metal. With four water molecules, the coordination number would then be 7 . While the computational study suggests that $\mathrm{Isa}^{-}$probably acts as a tridentate ligand in solution, bidentate coordination is found in the $\mathrm{CaIsa}_{2}$ single-crystal structure.

Selected bond lengths for the two models are listed in Table 7. In both cases the strongest interaction was found between Ca and O1 (2.375 $\AA$ for complex 3 and $2.297 \AA$ for complex 4). These lengths are similar to those found in the single-crystal structure.

Three hydrogen bonds are formed in both isomers of which the strongest ones are established between $\mathrm{H}(\mathrm{O} 4)$ and $\mathrm{O}^{\prime}$ (complex 3) as well as $\mathrm{H}(\mathrm{O} 2)$ and $\mathrm{O}^{\prime}$ (complex 4). Interestingly, the $\mathrm{H}$ atom of the $\mathrm{C} 4-\mathrm{OH}$ moiety (complex 4) appears to form hydrogen bonds both with the $\mathrm{C} 5-\mathrm{OH}$ group and one water.

In a similar way to $[\mathrm{CaGluc}]^{+},[\mathrm{CaIsa}]^{+}$has (at least) two isomers which are in dynamic equilibrium. Furthermore, the difference in free energy suggests that the equilibrium is

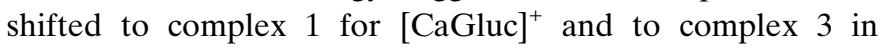
[CaIsa $^{+}$(Figs. 5 and 8, respectively). When four water molecules are present in the first coordination shell of $\mathrm{Ca}^{2+}$, sevenfold coordination is seemingly more favourable for $[\mathrm{CaIsa}]^{+}$than for $[\mathrm{CaGluc}]^{+}$.

\section{Conclusion}

The solid state structures of $\mathrm{CaGluc}_{2} \cdot \mathrm{H}_{2} \mathrm{O}$ and $\mathrm{CaIsa}_{2}$ have been determined using single-crystal X-ray diffraction and both are non-centrosymmetric orthorhombic structures comprising coordination polymers parallel to the $a$ axis. Distinguishing it from the isosaccharinate structure, adjacent metal centres in the $\mathrm{CaGluc}_{2} \cdot \mathrm{H}_{2} \mathrm{O}$ structure are linked by three $\mu$-oxo bridges. One of the gluconate ligands binds to three metal centres. In contrast, adjacent metal centres in the $\mathrm{CaIsa}_{2}$ structure are spanned by two isosaccharinate ligands. Both of these ligands separate the adjacent metals by binding one metal ion with a pair of hydroxy groups at one end of the ligand, while the second metal is bound by a carboxylate and a hydroxy group at the other end of the ligand. The calcium $\alpha$-Disosaccharinate complex is then eightfold coordinated, whereas the calcium ion in the calcium D-gluconate monohydrate crystal is coordinated to nine oxygen atoms. The $\mathrm{CaGluc}_{2} \cdot \mathrm{H}_{2} \mathrm{O}$ coordination polyhedron is that of a distorted triaugmented triangular prism and adjoining polyhedra of a given polynuclear chain share a triangular face. The coordination polyhedron in the isosaccharinate structure is a distorted Archimedean antiprism, each of which is isolated from its two neighbours by the bridging ligands. The two structures then have very different hydrogen-bond networks and packing arrangements.

The previously reported calcium $\alpha$-D-isosaccharinate structure has been improved upon, with the use of a synchrotron source providing data of sufficient quality to allow both the use of anisotropic displacement parameters for all of the non-hydrogen atoms and the location of the electron density associated with the hydroxy hydrogen sites.

Complementing the crystal structure determinations, solution structures of the $[\mathrm{CaGluc}]^{+}$and $[\mathrm{CaIsa}]^{+}$complexes have been explored by computational modelling, extending previous solution and computational studies. For $\mathrm{Gluc}^{-}$, two binding isomers are found with the $\mathrm{COO}^{-}$and $\mathrm{C} 3-\mathrm{OH}$ or the $\mathrm{COO}^{-}$and $\mathrm{C} 2-\mathrm{OH}$ groups being the binding sites. Strong hydrogen bonds are formed in both complexes, similar to those found in the crystal structures.

Two coordination isomers are found for the $[\mathrm{CaIsa}]^{+}$ complex. The $\mathrm{Isa}^{-}$is found to act as a tridentate ligand with the $\mathrm{COO}^{-}, \mathrm{C} 2-\mathrm{OH}$ and $\mathrm{C} 6-\mathrm{OH}$ or the $\mathrm{COO}^{-}, \mathrm{C} 4-\mathrm{OH}$ and $\mathrm{C} 6-\mathrm{OH}$ being the coordinating groups. These two isomers are most probably in dynamic equilibrium. When four water molecules are present in the first coordination shell of $\mathrm{Ca}^{2+}$, the sevenfold coordination is seemingly more favourable for $[\mathrm{CaIsa}]^{+}$than for $[\mathrm{CaGluc}]^{+}$.

\section{Acknowledgements}

The calcium gluconate X-ray diffraction data for calcium gluconate were collected at the UK National Crystallography Facility and the support and assistance of Professor Simon Coles, Dr Graham Tizzard and Dr Peter Horton is gratefully acknowledged. The synchrotron X-ray diffraction data for calcium isosaccharinate were collected at beamline P13 operated by the EMBL (Hamburg) at the PETRA III storage ring (DESY, Hamburg, Germany). We would like to thank Johanna Hakanpää and Guillaume Pompidor for their assistance in using the beamline. All support is highly appreciated.

\section{Funding information}

The following funding is acknowledged: Nemzeti Kutatási, Fejlesztési és Innovációs Hivatal (grant No. NKFIH K 124 265); GINOP (grant No. GINOP-2.3.2-15-2016-00013).

\section{References}

Albright, J. N. (1972). J. Chem. Phys. 56, 3783-3786.

Almond, M., Belton, D., Humphreys, P. N. \& Laws, A. P. (2016). Carbohydr. Res. 427, 48-54.

Badyal, Y. S., Barnes, A. C., Cuello, G. J. \& Simonson, J. M. (2004). J. Phys. Chem. A, 108, 11819-11827.

Baston, G. M. N., Berry, J. A., Bond, K. A., Boult, K. A. \& Linklater, C. M. (1994). Radiochim. Acta, 66-67, 437-442.

Baston, G. M. N., Berry, J. A., Bond, K. A., Brownsword, M. \& Linklater, C. M. (1992). Radiochim. Acta, 58-59, 349-356.

Becke, A. D. (1988). Phys. Rev. A, 38, 3098-3100.

Berner, U. (1990). A thermodynamic description of the evolution of pore water chemistry and uranium speciation during the degradation of cement in Switzerland: Nationale Genossenschaft für die Lagerung radioaktiver Abfälle (NAGRA).

Berner, U. R. (1992). Waste Manage. (Oxford), 12, 201-219.

Berry, J. A., Bond, K. A., Ferguson, D. R. \& Pilkington, N. J. (1991). Radiochim. Acta, 52-53, 201-210.

Birjkumar, K. H., Bryan, N. D. \& Kaltsoyannis, N. (2012). Dalton Trans. 41, 5542-5552.

Bol, W., Gerrits, G. J. A. \& van Panthaleon Eck, C. L. (1970). J. Appl. Cryst. 3, 486-492. 
Brockhauser, S., Ravelli, R. B. G. \& McCarthy, A. A. (2013). Acta Cryst. D69, 1241-1251.

Burkhardt, A., Pakendorf, T., Reime, B., Meyer, J., Fischer, P., Stübe, N., Panneerselvam, S., Lorbeer, O., Stachnik, K., Warmer, M., Rödig, P., Göries, D. \& Meents, A. (2016). Eur. Phys. J. Plus, 131, $1-9$.

Carl, D. R. \& Armentrout, P. B. (2012). J. Phys. Chem. A, 116, 38023815.

Colàs, E., Grivé, M. \& Rojo, I. (2013a). J. Solution Chem. 42, 15451557.

Colàs, E., Grivé, M., Rojo, I. \& Duro, L. (2013b). J. Solution Chem. 42, 1680-1690.

Coles, S. J. \& Gale, P. A. (2012). Chem. Sci. 3, 683-689.

Cummings, S., Enderby, J. E. \& Howe, R. A. (1980). J. Phys. C Solid State, 13, 1-8.

Di Tommaso, D., Ruiz-Agudo, E., de Leeuw, N. H., Putnis, A. \& Putnis, C. V. (2014). Phys. Chem. Chem. Phys. 16, 7772-7785.

Dolomanov, O. V., Bourhis, L. J., Gildea, R. J., Howard, J. A. K. \& Puschmann, H. (2009). J. Appl. Cryst. 42, 339-341.

Dudás, C., Kutus, B., Böszörményi, É., Peintler, G., Kele, Z., Pálinkó, I. \& Sipos, P. (2017). Dalton Trans. 46, 13888-13896.

Farrugia, L. (1999). J. Appl. Cryst. 32, 837-838.

Farrugia, L. J. (2012). J. Appl. Cryst. 45, 849-854.

Flack, H. D. (2014). Chimia (Aarau), 68, 26-30.

Frisch, M. J. et al. (2009). Gaussian09. Rev. A.02. Gaussian, Inc., Wallingford, CT, USA.

Gabadinho, J. et al. (2010). J. Synchrotron Rad. 17, 700-707.

Gaona, X., Montoya, V., Colàs, E., Grivé, M. \& Duro, L. (2008). J. Contam. Hydrol. 102, 217-227.

Giroux, S., Aury, S., Henry, B. \& Rubini, P. (2002). Eur. J. Inorg. Chem. 2002, 1162-1168.

Glaus, M. A., Laube, A. \& Van Loon, L. R. (2006). Waste. Manag. 26, 741-751.

Glaus, M. A. \& Van Loon, L. R. (2008). Environ. Sci. Technol. 42, 2906-2911.

Glaus, M., van Loon, L. R., Achatz, S., Chodura, A. \& Fischer, K. (1999). Anal. Chim. Acta, 398, 111-122.

Groom, C. R., Bruno, I. J., Lightfoot, M. P. \& Ward, S. C. (2016). Acta Cryst. B72, 171-179.

Hall, S. R., du Boulay, D. J. \& Olthof-Hazekamp, R. (2000). Editors. Xtal3.7 System. University of Western Australia, Australia. http:// xtal.sourceforge.net/

Hewish, N. A., Neilson, G. W. \& Enderby, J. E. (1982). Nature, 297, 138-139.

Hübschle, C. B., Sheldrick, G. M. \& Dittrich, B. (2011). J. Appl. Cryst. 44, 1281-1284.

Jeffrey, G. A. \& Fasiska, E. J. (1972). Carbohydr. Res. 21, 187-199.

Kabsch, W. (2010). Acta Cryst. D66, 125-132.

Knill, C. J. \& Kennedy, J. F. (2003). Carbohydr. Polym. 51, 281-300.

Lee, C., Yang, W. \& Parr, R. G. (1988). Phys. Rev. B, 37, 785-789.

Lis, T. (1981). Acta Cryst. B37, 1957-1959.

Lis, T. (1983). Carbohydr. Res. 122, 23-29.

Lis, T. (1984a). Acta Cryst. C40, 374-376.

Lis, T. (1984b). Acta Cryst. C40, 376-378.

Masone, M. \& Vicedomini, M. (1981). Ann. Chim. (Rome), 71, 517523.

Megyes, T., Bakó, I., Bálint, S., Grósz, T. \& Radnai, T. (2006). J. Mol. Liq. 129, 63-74.

Megyes, T., Grósz, T., Radnai, T., Bakó, I. \& Pálinkás, G. (2004). J. Phys. Chem. A, 108, 7261-7271.

Momany, F. A., Appell, M., Strati, G. \& Willett, J. L. (2004). Carbohydr. Res. 339, 553-567.

Momma, K. \& Izumi, F. (2011). J. Appl. Cryst. 44, 1272-1276.

NAGRA (1990). Endlager für schwach- und mittelaktive Abfälle (Endlager SMA). Bericht zur Langzeitsicherheit des Endlagers SMA Am Standort Welienberg (Gemeinde Wolfenschiessen, NW
Nationale Genossenschaft für die Lagerung radioaktiver Abfälle (NAGRA), Wettingen, Switzerland.

Nair, R. M., Sudarsanakumar, M. R., Suma, S., Prathapachandra Kurup, M. R. \& Sudhadevi Antharjanam, P. K. (2016). Inorg. Chem. Commun. 63, 81-85.

Nuclear Decommissioning Agency (2010). Geological Disposal Near-Field Evolution Status Report.

Norrestam, R., Werner, P. E. \& von Glehn, M. (1968). Acta Chem. Scand. 22, 1395-1403.

Pallagi, A., Bajnóczi, É. G., Éva, G., Canton, S. E., Bolin, T., Peintler, G., Kutus, B., Kele, Z., Pálinkó, I. \& Sipos, P. (2014). Environ. Sci. Technol. 48, 6604-6611.

Pallagi, A., Csendes, Z., Kutus, B., Czeglédi, E., Peintler, G., Forgó, P., Pálinkó, I. \& Sipos, P. (2013). Dalton Trans. 42, 8460-8467.

Pallagi, A., Sebők, P., Forgó, P., Jakusch, T., Pálinkó, I. \& Sipos, P. (2010). Carbohydr. Res. 345, 1856-1864.

Panagiotopoulos, N. C., Jeffrey, G. A., La Placa, S. J. \& Hamilton, W. C. (1974). Acta Cryst. B30, 1421-1430.

Parsons, S., Flack, H. D. \& Wagner, T. (2013). Acta Cryst. B69, 249 259.

Probst, M. M., Radnai, T., Heinzinger, K., Bopp, P. \& Rode, B. M. (1985). J. Phys. Chem. 89, 753-759.

Rai, D., Rao, L. \& Xia, Y. (1998). J. Solut. Chem. 27, 1109-1122.

Rigaku Oxford Diffraction (2015). CrysAlis PRO. Rigaku Oxford Diffraction, Yarnton, England.

Rojo, H., Tits, J., Gaona, X., Garcia-Gutiérrez, M., Missana, T. \& Wieland, E. (2013). Radiochimica Acta, 101, 133-138.

Shaw, P. B., Robinson, G. F., Rice, C. R., Humphreys, P. N. \& Laws, A. P. (2012). Carbohydr. Res. 349, 6-11.

Sheldrick, G. M. (2008). Acta Cryst. A64, 112-122.

Sheldrick, G. M. (2015a). Acta Cryst. A71, 3-8.

Sheldrick, G. M. (2015b). Acta Cryst. C71, 3-8.

Spek, A. L. (2003). J. Appl. Cryst. 36, 7-13.

Spångberg, D., Hermansson, K., Lindqvist-Reis, P., Jalilehvand, F., Sandström, M. \& Persson, I. (2000). J. Phys. Chem. B, 104, $10467-$ 10472.

Svensson, M., Berg, M., Ifwer, K., Sjöblom, R. \& Ecke, H. (2007). J. Hazard. Mater. 144, 477-484.

Tajmir-Riahi, H. A. (1990). J. Inorg. Biochem. 39, 33-41.

Tits, J., Wieland, E. \& Bradbury, M. H. (2005). Appl. Geochem. 20, 2082-2096.

Tomasi, J., Mennucci, B. \& Cammi, R. (2005). Chem. Rev. 105, 2999 3093.

Tongraar, A., T-Thienprasert, J., Rujirawat, S. \& Limpijumnong, S. (2010). Phys. Chem. Chem. Phys. 12, 10876-10887.

Van Loon, L. R. \& Glaus, M. A. (1997). J. Environ. Polym. Degrad. 5, 97-109.

Van Loon, L. R. \& Glaus, M. A. (1998). Experimental and Theoretical Studies on Alkaline Degradation of Cellulose and its Impact on the Sorption of Radionuclides, Paul Scherrer Institute (PSI), Villigen, Swizerland.

Van Loon, L. R., Glaus, M. A., Laube, A. \& Stallone, S. (1999). Radiochim. Acta, 86, 183-189.

Van Loon, L. R., Glaus, M. A., Stallone, S. \& Laube, A. (1997). Environ. Sci. Technol. 31, 1243-1245.

Whistler, R. L. \& BeMiller, J. N. (1963). In Methods in Carbohydrate Chemistry. Vol. 2: Reactions of Carbohydrates, edited by M. L. Wolfrom \& J. N. BeMiller, pp. 477-479. New York: Academic Press.

Wieland, E. \& Van Loon, L. R. (2003). Cementitious Near-Field Sorption Data Base for Performance Assessment of an ILW Repository in Opalinus Clay, Paul Scherrer Institute (PSI), Villigen, Switzerland.

Zhang, Z., Bottenus, B., Clark, S. B., Tian, G. X., Zanonato, P. \& Rao, L. (2007). J. Alloys Compd. 444-445, 470-476.

Zhang, Z., Helms, G., Clark, S. B., Tian, G. X., Zanonato, P. \& Rao, L. (2009). Inorg. Chem. 48, 3814-3824. 